\title{
Experimental Research on the Thermal Performance of Composite PCM Hollow Block Walls and Validation of Phase Transition Heat Transfer Models
}

\author{
Yuan Zhang, ${ }^{1}$ Sunqi Zhuang, ${ }^{2}$ Qian Wang, ${ }^{1}$ and Jiapeng $\mathrm{He}^{2}$ \\ ${ }^{1}$ School of Energy and Power Engineering, Jiangsu University, 301 Xuefu Road, Zhenjiang, Jiangsu 212013, China \\ ${ }^{2}$ College of Urban Construction, Nanjing Tech University, Nanjing, China
}

Correspondence should be addressed to Yuan Zhang; yuanzhangnj@126.com

Received 1 September 2015; Revised 27 December 2015; Accepted 29 December 2015

Academic Editor: Fernando Lusquiños

Copyright (C) 2016 Yuan Zhang et al. This is an open access article distributed under the Creative Commons Attribution License, which permits unrestricted use, distribution, and reproduction in any medium, provided the original work is properly cited.

\begin{abstract}
A type of concrete hollow block with typical structure and a common phase change material (PCM) were adopted. The PCM was filled into the hollow blocks by which the multiform composite PCM hollow blocks were made. The temperature-changing hot chamber method was used to test the thermal performance of block walls. The enthalpy method and the effective heat capacity method were used to calculate the heat transfer process. The results of the two methods can both reach the reasonable agreement with the experimental data. The unsteady-state thermal performance of the PCM hollow block walls is markedly higher than that of the wall without PCM. Furthermore, if the temperature of the PCM in the wall does not exceed its phase transition temperature range, the PCM wall can reach high thermal performance.
\end{abstract}

\section{Introduction}

As the building energy consumption increases, the energysaving technology in buildings has become one of the hot fields in the world; meanwhile, people's demand on the indoor thermal comfort also increases continuously. One of the traditional ways to solve this problem is to introduce thermal insulation materials into building envelope to enhance the thermal performance of wall. Traditional thermal insulation materials have low thermal conductivities which can effectively reduce the heat flow through the building envelope; however, they are mostly organic thermal insulation materials with low specific heat capacity. This can probably result in the indoor temperature fluctuation with large amplitude and frequency, which reduces the indoor thermal comfort degree, gives rise to the frequent open and close of air-conditioning device, and decreases the opportunity of device operating under the optimum condition, which increases the energy consumption of device. In addition, the fire safety hidden trouble is accompanied, and the thermal insulation material does not have a lifetime as long as the building itself (the general service life of the organic thermal insulation material is 10 to 20 years). Therefore, people start to find new and better methods to save energy.

It is one of the potential ways to use phase change material (PCM) into building envelope. The proper use of the latent heat of phase transition effect can substantially increase the thermal capacity of building envelope. By doing this, the heat flow into building envelope in daytime is conserved; when the outdoor air's temperature falls to a low value in night time, the PCM releases heat and then makes the conserved heat back to the outside. In this way, the heat entering into the interior of the room throughout a day will be remarkably reduced; furthermore, the peak of heat entering building envelope in daytime will enter into the interior of the room at dusk or night with a lower peak value and larger time lag because of the decrement and delay effects. At this time, the indoor cooling load is reduced; also, the electric charge is in the valley time period, by which the indoor thermal comfort degree is improved and the money is saved.

At present, a lot of researchers studied the thermal performance of the building envelope outfitted with PCM layer. Aelenei used a new structure of wall with photovoltaic board and PCM board and calculated and tested the application 
effect under the climate of winter. The results indicated that the electrical energy was saved by $10 \%$ and the efficiency of the whole system reached $20 \%$ by using this type of wall [1]. Ahmed et al. introduced the PCM (paraffin) into the wall of the truck box which was used for the refrigeration of things. The test results demonstrated that the peak heat flow rate entering the truck box was averagely reduced by $29.1 \%$ when all the walls were outfitted with PCM; if one wall of the walls was outfitted with PCM, the heat flow rate can be decreased for $11.3 \%-43.8 \%$; the heat flow rate that entered the truck box every day can be reduced for $16.3 \%$ [2]. Alqallaf and Alawadhi analyzed the thermal performance of a concrete roof deck outfitted with PCM. The test results indicated that the heat gain became lower with the increasing amount of PCM; furthermore, the heat gain was influenced by the phase transition temperature of the PCM [3]. Bontemps et al. applied PCM into the wall of an experimental box with twin-box structure. The experimental box was placed under the environment of the local typical outdoor climate. The test results demonstrated that the temperature fluctuation inside the test box with PCM was significantly lower than that of the box without PCM [4]. Borreguero et al. tested the thermal performance of a gypsum board outfitted with PCM. The result showed that the thermal storage capacity of the gypsum board was strengthened by the increasing amount of PCM; meanwhile, the temperature fluctuation inside the wall was reduced; in addition, containing the same thermal performance, by increasing 5\% (mass fraction) amount of PCM inside the board, the thickness of the board can be decreased for 8.5\% [5]. Cabeza et al. built a concrete room with actual size. The south and west walls and the roof were outfitted with 5\% PCM, and the room was exposed to the natural environment. The results demonstrated that the thermal inertia of the wall with PCM was remarkably higher than the wall without PCM, and the interior surface temperature of the PCM wall was lower (reducing for 0 to $2^{\circ} \mathrm{C}$ ); the peak heat was shifted for about two hours by the PCM wall [6]. Castell et al. built the house using two types of traditional perforated bricks with and without PCM. The houses were tested under the typical climate of Spain. The results showed that the PCM made the indoor peak temperature reduce for about $0.9^{\circ} \mathrm{C}$ and $0.73^{\circ} \mathrm{C}$, and the energy consumption reduced for $15 \%$ and $17 \%$ [7].

It can be seen from the above research that the building envelope outfitted with PCM can reach better thermal performance. At present, the study of the phase transition heat transfer model is mostly around the one-dimensional models $[4,5,8]$. However, it is easy to leak and be damaged and occupies the thickness of wall, if the PCM exists in building envelope with the form of one layer. The hollow brick wall and hollow block wall are widely used in some parts of world for energy conservation now. If the PCM is properly put into the holes of the hollow bricks and hollow blocks, the construction procedure will be simplified and the negative influences will be avoided with maintaining high thermal performance.

On the field of multidimensional heat transfer, Antoniadis et al., using Comsol Multiphysics software [9] and twodimensional finite element method, analyzed the impacts of the hole rows, hole thickness, and the staggered or unstaggered arrangement of hole rows on the thermal performance of hollow brick, taking the effective thermal conductivity as the evaluation index [10]. Arendt, using two-dimensional energy equation, studied the impacts of hollow ratio on the steady-state and unsteady-state thermal parameters of hollow bricks, with the evaluation indexes of time lag, decrement factor, and equivalent thermal conductivity [11]. Li et al. studied the heat transfer process of the hollow bricks with different structures using the Tri-diagonal Matrix (TDMA) method and Alternating Direction Implicit (ADI) method $[12,13]$. The computational efficiency and accuracy of the methods are both superior to or equivalent to the Gaussian elimination method [14], which are appropriate for the solution of multidimensional heat transfer problems of the nonhomogeneous materials such as hollow blocks [15, 16]. Mackerle et al. analyzed the thermal performance of a concrete roof outfitted with PCM using three-dimensional heat conduction model and finite element method. In the mathematical model, the specific heat of PCM within the phase transition temperature range was equivalent to a certain value. The discrete equations were solved by preconditional generalized minimum residual (PGMR) [17] solver. This concrete roof had some cylindrical holes inside, which were filled with PCM (A39). The numerical calculation and experimental test were performed on the roofs with and without PCM, respectively. The results demonstrated that the maximum errors between the calculation results and the experimental data were $7.25 \%$ and $7.4 \%$, and there was reasonable agreement between calculation results obtained by the PCM mathematical model and the experimental data [3]. Carbonari et al. developed a two-dimensional phase transition heat transfer model. He used the model and finite element method calculated the heat transfer process of a type of wall board with PCM layer. After the comparison between the calculation results and the experimental data, it was found that a good agreement is achieved [18]. It can be known that, at present, the study on the multidimensional heat transfer process of the constant-property material wall is relatively sufficient but that of the composite PCM wall is insufficient.

In consideration of the reasons above, a type of concrete hollow blocks in typical structure and a commonly used phase change material (PCM) were adopted and the multiform composite PCM hollow blocks were produced in this paper. The PCM was put into different positions of hollow blocks. The temperature-changing hot chamber method was used to test the thermal performance of the hollow block walls with or without PCM under different temperature conditions; meanwhile, the two-dimensional enthalpy model and effective heat capacity model were used to calculate the phase transition heat transfer process under the conditions of experiments. The results of the models were validated by the experimental data, and the thermal performances of the hollow block walls with and without PCM and the walls with the PCM at different positions were compared. The difference on the thermal performance of each wall was analyzed, which provides the data reference and guide for the engineering application of composite PCM hollow block wall. 


\section{Mathematical Models}

2.1. Assumptions. To simplify the heat transfer model, the following assumptions were made: (1) all the materials were considered to be thermally homogeneous and isotropic; (2) because the heat transfer process was mainly heat conduction, the thermal conductivity of the liquid PCM was considered to be not changed; (3) because the specific volume ratio of the solid state to that of the liquid state was less than 1.15, the volume change of the PCM during the phase change process was ignored; (4) the supercooling effect during the freezing process and the natural convection effect were ignored (the used PCM in the experiment and calculation was the composite PCM which was the mixture of the PCM and gypsum in a certain ratio; the natural convection effect was effectively restrained); (5) the equivalent thermal conductivity was applied for the air cavities inside the blocks [19]; (6) because the net heat flow was 0 on the vertical direction of wall, the heat transfer in the computational domain was simplified to be two-dimensional heat transfer, and the total heat flow was on the direction of thickness (the boundaries of other directions were adiabatic, where the second type thermal boundary condition was applied).

For point (4), there are some explanations which are worthy to state. According to the formula, the Grashof and Prandtl numbers can be calculated as $\mathrm{Gr}=g \alpha \Delta t l^{3} / \nu^{2}$ and $\operatorname{Pr}=v / a$. After the calculations, for the side holes with air in the experimental hollow blocks, the average $\mathrm{Gr}$ is calculated as 0.0167 , and the 0.3998 for the middle holes with air. The average Pr for the side holes with air and the middle holes with air is around 0.699. The average Gr for the side holes with air and the middle holes with air is relatively small, which demonstrates that the buoyancy force is small, relative to the viscous force. Meanwhile, the average Pr is relatively large, which indicates the obvious influence of viscidity during the heat transfer process. Therefore, it can be seen that the convection effect in the holes with air is unapparent and the main heat transfer approach is heat conduction. For the holes with PCM, the used PCM in the experiment and calculation was the composite PCM which was the mixture of the PCM and gypsum in a certain ratio. Then the liquid PCM (if it has melted) exists in the microvoid of the solid gypsum. Because of these, the natural convection effect was effectively restrained, the value of the Gr for the holes with PCM becomes very small, and the Pr is the same as the status of the holes with air. With the situations above, we assumed the natural convection to be negligible and we considered that it will not produce large errors in the calculations.

For point (6), it is worthy to explain that, according to the instruction book of the device, the heat loss of the chambers and the wall frames is less than 5\%. Furthermore, the thermal conductivity of the insulation material inside the frames of chambers (extruded polystyrene) is low enough $(0.029 \mathrm{~W} / \mathrm{m} \cdot \mathrm{K})$ and the thickness of the frames is large enough (larger than $0.15 \mathrm{~m}$ ). Therefore, we consider that the heat losses through the chambers and the wall frames have little impact on the accuracy of the experimental data.
2.2. Governing Equation. In this research, the traditional two-dimensional heat transfer equation was used to solve the problem of the hollow block wall without PCM [20], and the two-dimensional enthalpy model and effective heat capacity model were adopted for the hollow block wall with PCM.

\subsubsection{Two-Dimensional Enthalpy Model. One has}

$$
\rho \frac{\partial H}{\partial \tau}=\lambda\left(\frac{\partial^{2} T}{\partial x^{2}}+\frac{\partial^{2} T}{\partial y^{2}}\right)
$$

where $\rho, \lambda$, and $H$ were the density, thermal conductivity, and enthalpy of PCM, respectively. The thickness and width directions were represented by $x$ and $y$, and the temperature at any point in time $\tau$ was $T$. The enthalpy of PCM was calculated by

$$
\begin{aligned}
& H \\
& = \begin{cases}c_{p, s} \cdot T & T<T_{m}-\varepsilon \\
c_{p, s} \cdot T_{m}+\frac{L}{2 \varepsilon} \cdot\left[T-\left(T_{m}-\varepsilon\right)\right] & T_{m}-\varepsilon \leq T \leq T_{m}+\varepsilon \\
c_{p, s} \cdot T_{m}+L+c_{p, l} \cdot\left[T-\left(T_{m}+\varepsilon\right)\right] & T>T_{m}+\varepsilon,\end{cases}
\end{aligned}
$$

where $c_{p, s}$ and $c_{p, l}$ were the specific heat of the PCM in its solid and liquid states, respectively, $T_{m}$ was the mean temperature of the phase transition temperature range. The phase change radius $\varepsilon$ represented the half range of the phase change temperature range and $L$ was the latent heat during phase change. The temperature range of phase transition was from $T_{m}-\varepsilon$ to $T_{m}+\varepsilon$. When $T<T_{m}-\varepsilon$ or when $T>T_{m}+\varepsilon$, the value of $c_{p, s}$ was equal to the value of $c_{p, l}\left(=2.919 \mathrm{~kJ} \cdot \mathrm{kg}^{-1} \cdot \mathrm{K}^{-1}\right)$; when $T_{m}-\varepsilon \leq T \leq T_{m}+\varepsilon$, the value of $c_{p, s}$ was equal to $c_{p \text {,equ }}=L / 2 \varepsilon$, where $c_{p \text {, equ }}$ was the equivalent specific heat of the PCM during phase change.

\subsubsection{Two-Dimensional Effective Heat Capacity Model. One} has

$$
\begin{aligned}
\rho c_{\mathrm{eff}} \frac{\partial T}{\partial \tau} & =\lambda\left(\frac{\partial^{2} T}{\partial x^{2}}+\frac{\partial^{2} T}{\partial y^{2}}\right), \\
c_{\mathrm{eff}} & =\frac{d H / d \tau}{(m \cdot(d T / d \tau))},
\end{aligned}
$$

where $\rho$ and $\lambda$ represented the density and the thermal conductivity of the PCM, respectively. $c_{\text {eff }}$ was the effective heat capacity of the PCM, which was calculated using (4). The parameters $x$ and $y$ were the thickness and width directions, and $T$ was the temperature of the specimen at a point in time $\tau ; d H / d \tau$ and $m$ were the heat flow rate across the PCM and the mass of the PCM. The heating or cooling rate of the PCM was given by $d H / d \tau$.

2.3. Initial and Boundary Conditions. Because the parameters were tested under the periodical thermal boundary conditions in the experiments, four temperature periods were performed in each experiment to eliminate the impact of the 
TABLE 1: Thermal-physical parameters of PCM (Capric Acid).

\begin{tabular}{lccccc}
\hline $\begin{array}{l}\text { Density } \rho \\
\left(\mathrm{kg} \cdot \mathrm{m}^{-3}\right)\end{array}$ & $\begin{array}{c}\text { Sensible heat } c \\
\left(\mathrm{~J} \cdot \mathrm{kg}^{-1} \cdot \mathrm{K}^{-1}\right)\end{array}$ & $\begin{array}{c}\text { Latent heat } L \\
\left(\mathrm{~J} \cdot \mathrm{kg}^{-1}\right)\end{array}$ & $\begin{array}{c}\text { Thermal conductivity } \lambda \\
\left(\mathrm{W} \cdot \mathrm{m}^{-1} \cdot \mathrm{K}^{-1}\right)\end{array}$ & $\begin{array}{c}\text { Melting peak } \\
\text { temperature range }\left({ }^{\circ} \mathrm{C}\right)\end{array}$ & $\begin{array}{c}\text { Freezing peak } \\
\text { temperature range }\left({ }^{\circ} \mathrm{C}\right)\end{array}$ \\
\hline 886 (liquid) & 2919 & $\begin{array}{c}138040 \text { (melting) } \\
150970 \text { (freezing) }\end{array}$ & 0.152 & $31.4 \sim 34.5$ & $24.6 \sim 27.1$ \\
1004 (solid) & 2919 & & & \\
\hline
\end{tabular}

initial condition on the testing results. The initial temperature was shown as follows:

$$
\left.T(x, y, \tau)\right|_{\tau=0}=T_{\text {init }},
$$

where $T(x, y, \tau)$ was the temperature at point $(x, y)$ at time $\tau$. $T_{\text {init }}$ was the initial temperature.

The third type thermal boundary condition was applied when $x=1$ (exterior surface on the thickness direction) and $x=N_{x}$ (interior surface on the thickness direction):

$$
\begin{aligned}
x= & 1: \rho c \frac{\partial T}{\partial \tau} d x d y=\left.\lambda\left(\frac{\partial T}{\partial x}\right)\right|_{P-E} d y+h_{a} T_{f a} \\
& \left.-T_{P}\right) d y+\left.\lambda\left(\frac{\partial T}{\partial y}\right)\right|_{P-N} d x-\left.\lambda\left(\frac{\partial T}{\partial y}\right)\right|_{S-P} d x \\
x & =N_{x}: \rho c \frac{\partial T}{\partial \tau} d x d y=-\left.\lambda\left(\frac{\partial T}{\partial x}\right)\right|_{W^{\prime}-P^{\prime}} d y+h_{b}\left(T_{f b}\right. \\
& \left.-T_{P^{\prime}}\right) d y+\left.\lambda\left(\frac{\partial T}{\partial y}\right)\right|_{P^{\prime}-N^{\prime}} d x-\left.\lambda\left(\frac{\partial T}{\partial y}\right)\right|_{S^{\prime}-P^{\prime}} d x,
\end{aligned}
$$

where $N_{x}$ was the total number of the meshes on the $x$ direction; point $p$ and $p^{\prime}$ were the boundary meshes when $x=1$ and $x=N_{x} ; E, N$, and $S$ were the points right to, above, and under point $p ; W^{\prime}, N^{\prime}$, and $S^{\prime}$ were the points left to, above, and under point $p^{\prime} ; h_{a}, T_{f a}, h_{b}$, and $T_{f b}$ were the convective heat transfer coefficients and boundary air temperatures when $x$ was equal to 1 and $N_{x}$, respectively. Each item of the two equations took the positive value when heat flowed into the point $p$ (or $p^{\prime}$ ) and negative value when heat flowed out of the point $p$ (or $p^{\prime}$ ).

The boundaries on the direction of $y$ (width direction, when $y=1$ and $y=N_{y}, N_{y}$ was the total number of the meshes on the $y$ direction) were adiabatic (the second type thermal boundary condition). The equation is

$$
-\left.\lambda \frac{\partial T}{\partial y}\right|_{y=1}=-\left.\lambda \frac{\partial T}{\partial y}\right|_{y=N_{y}}=f(\tau),
$$

where $f(\tau)$ was the heat flow function in which the independent variable was time $\tau, f(\tau)=0$.

2.4. Numerical Method. The point iteration method was used for the two-dimensional numerical calculation in this work. The governing equations and boundary conditions were discretized by Finite Difference Method (FDM) [21, 22]. The sizes of the mesh and time steps were $0.005 \mathrm{~m}$ and $2 \mathrm{~s}$, which guarantees that the results were independent of the used mesh and the time step sizes. Central differences were applied in space step while a fully implicit finite difference scheme and forward differences were applied in time step. The GaussSeidel scheme was employed in iteration. The convergence criterion is shown as in (8). The calculation program was developed in MATLAB environment [23]:

$$
\max |T(x, y, \tau)-T(x, y, \tau+1)| \leq 10^{-10},
$$

where $T(x, y, \tau)$ and $T(x, y, \tau+1)$ were the temperatures of the point $(x, y)$ at the time of $\tau$ and $\tau+1$, respectively.

\section{Experiments and Models Validation of Composite PCM Hollow Block Walls}

3.1. PCM and Composite PCM Hollow Blocks. Figure 1 is the schematic diagram of the four blocks used in experiments (the shaded part in the figures is PCM), they are the hollow block without PCM (Block 1), the block with a hole row of PCM which is near the left surface (Block 2, the left side of the block wall was disposed as the outdoor side, and the right side was disposed as the indoor side), the block with a hole row of PCM which is in the middle of the block (Block 3), and the block with a hole row of PCM which is near the right surface (Block 4), respectively. With filling PCM into the different rows of blocks, and taking the block without PCM as a reference, the thermal performance of composite PCM hollow block walls was analyzed. The PCM used in the experiments is Capric Acid. The thermal-physical parameters are shown in Table $1[24,25]$.

After the sealing and screeding on the undersurfaces of the corresponding holes of blocks with cement slurry sitting method (CSSM), the mixture of the PCM and gypsum was filled into different rows of holes in the blocks, as shown in Figure 2. Because the holes in the middle part of blocks were thicker than the side holes, the amount of PCM in each row of holes should be equal with maintaining the comparability; therefore, the material in each row of holes was the mixture of the PCM and gypsum in different proportions, and the mass of the PCM in each hole was $0.314 \mathrm{~kg}$. In addition, four thermocouples were pasted on the surfaces of the middle holes to test the varied temperatures on the surfaces of the PCM layer in Block 3 wall. In the calculations, the compound specific heat was used to calculate the heat transfer of the composite PCM, which was obtained by weighting the mass ratio of the PCM and gypsum.

3.2. Experimental Methodology and Conditions. The temperature-changing hot chamber method [20] was used in this research. The experimental device is in Figure 3. Both the left chamber and the right chamber can stabilize the temperatures inside and change them dynamically in the experiment. In order to maintain the adiabatic condition around the 


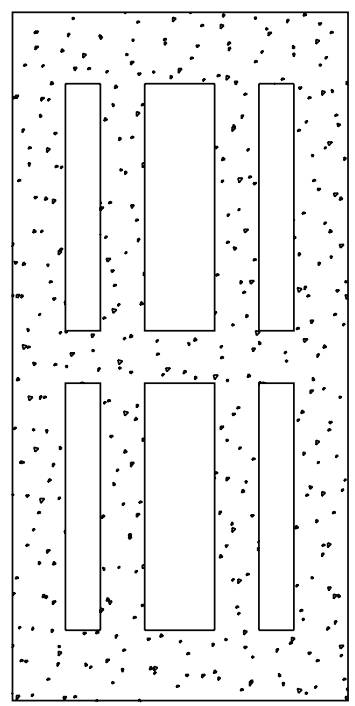

(a) Block 1

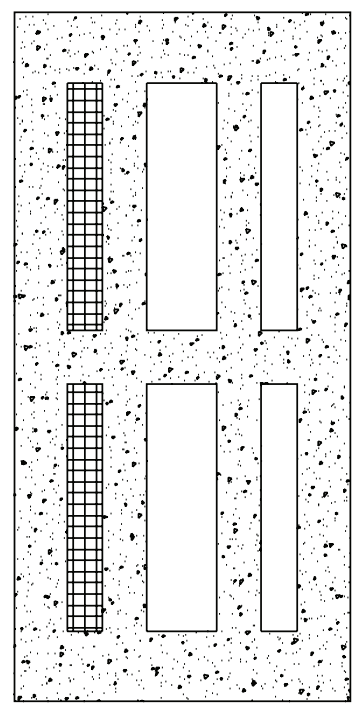

(b) Block 2

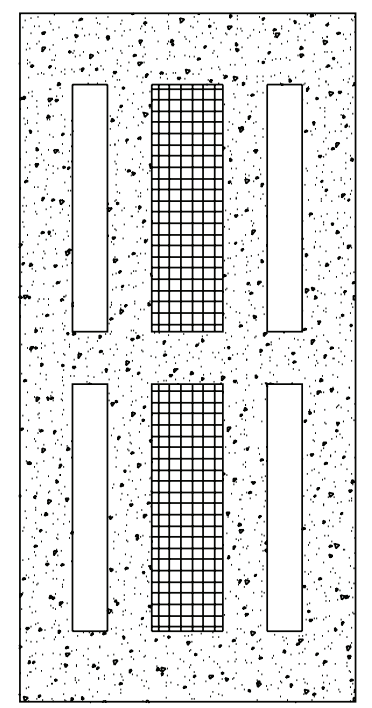

(c) Block 3

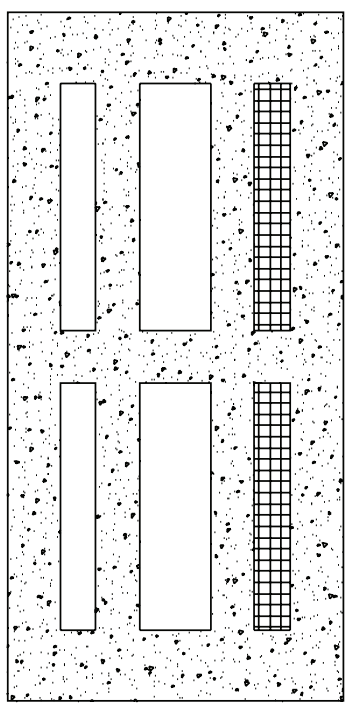

(d) Block 4

FIGURE 1: Schematic diagram of the PCM's positions in the blocks.

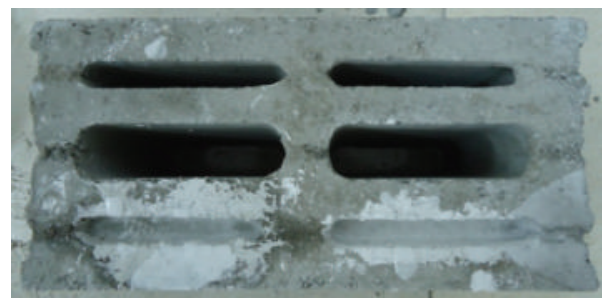

(a) PCM in the side holes (Block 2 and Block 4)

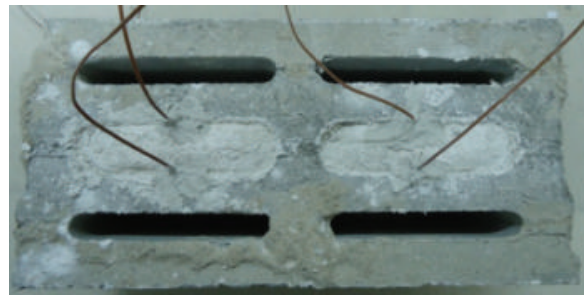

(b) PCM in the middle holes (Block 3)

FIGURE 2: PCM blocks.

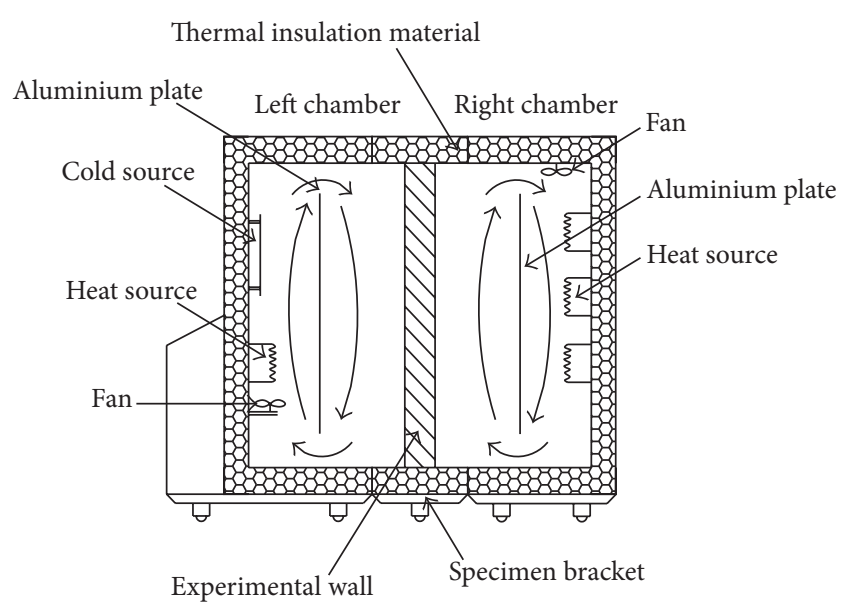

FIgURE 3: Experimental device.

experimental wall, the frames of the specimen bracket and the two chambers were treated to be approximately adiabatic. In the experiments, the temperatures on the two surfaces of wall were tested by the uniformly distributed thermocouples (nine thermocouples for each surface of the wall) and recorded by data logger.
Each block wall was tested under the common four boundary temperature conditions shown in Table 2; besides, for further exploration of the composite PCM blocks, the walls of Block 2, Block 3, and Block 4 were tested under the additional four boundary temperature conditions, respectively. In the right chamber of the experiments, the adiabatic condition was maintained around the frames but the temperature was not controlled; therefore, the temperature in the right chamber was influenced by the varied temperature of the right surface. Before the experiments, by multiple tests, the convective heat transfer coefficients on the left and right surfaces of wall were nearly stabilized at the values around $20.0 \mathrm{~W} / \mathrm{m}^{2} \cdot \mathrm{K}$ and $11.0 \mathrm{~W} / \mathrm{m}^{2} \cdot \mathrm{K}$.

3.3. The Uncertainty of the Experimental Data. The main devices used in the experiment are left and right chambers, temperature controller, data logger, thermocouples, and cooling and heating units. The temperature amplitude inside the left and right chambers is equal to or lower than $0.5^{\circ} \mathrm{C}$, and the heat loss of the chambers is lower than $5 \%$. Because the tested data are transient varied temperatures, the devices that influence the accuracy of the experimental data are the thermocouples. These thermocouples are all Ttype thermocouples. The range of measurement is $-50^{\circ} \mathrm{C}$ to 
TABLE 2: Boundary temperature ranges of each experiment.

\begin{tabular}{lc}
\hline Experiment number & $\begin{array}{c}\text { Left side air's } \\
\text { temperature } \\
\text { ranges }\left({ }^{\circ} \mathrm{C}\right)\end{array}$ \\
\hline Common boundary temperature ranges & \\
Temperature range 1 & $19.9 \sim 43.2$ \\
Temperature range 2 & $1.2 \sim 67.2$ \\
Temperature range 3 & $3.9 \sim 72.6$ \\
Temperature range 4 & $1.0 \sim 83.4$ \\
Additional boundary temperature ranges for & \\
Block 2 & \\
Temperature range 5 & $27.0 \sim 34.5$ \\
Temperature range 6 & $23.5 \sim 36.9$ \\
Temperature range 7 & $20.9 \sim 40.4$ \\
Temperature range 8 & $17.5 \sim 42.7$ \\
Additional boundary temperature ranges for & \\
Block 3 and Block 4 & \\
Temperature range 5 & $17.6 \sim 42.4$ \\
Temperature range 6 & $11.6 \sim 48.0$ \\
Temperature range 7 & $10.7 \sim 54.1$ \\
Temperature range 8 & $11.9 \sim 60.3$ \\
\hline
\end{tabular}

$100^{\circ} \mathrm{C}$ with the maximum uncertainty of $0.5^{\circ} \mathrm{C}$. Therefore, the maximum uncertainty of the experimental data is $0.5^{\circ} \mathrm{C}$.

3.4. Evaluation Indexes. To analyze the calculation accuracy, the standard errors and maximum absolute errors between the calculation curves and experimental curves were calculated using (9). The standard error reflects the average extent of the calculation curves deviating from the experimental curves, while the maximum absolute error reports the maximum deviation between the two curves:

$$
\begin{aligned}
\sigma & =\sqrt{\frac{\sum_{i=1}^{n}\left(N_{i}-N_{\text {sta }, i}\right)^{2}}{n}}, \\
\sigma^{\prime} & \\
& =\max \left(\left|N_{1}-N_{\text {sta }, 1}\right|,\left|N_{2}-N_{\text {sta }, 2}\right| \cdots\left|N_{n}-N_{\text {sta }, n}\right|\right),
\end{aligned}
$$

where $\sigma$ and $\sigma^{\prime}$ are standard error and maximum absolute error, respectively, $n$ is the amount of data, $i$ is the sequence number of data, $N_{i}$ is the $i$ th datum, and $N_{\text {sta, } i}$ is the $i$ th standard datum.

3.5. Models Validation and Experimental Analysis. Figures 4-7 are the curves of the surface temperatures (including the experimental data and calculation results), decrement factors, time lags, standard errors, and maximum absolute errors of the blocks in Figure 1 under the boundary temperature conditions in Table 2. The values of the temperature decrements, decrement factors, time lags, standard errors, and maximum absolute errors of each block wall are shown in Table 3.
3.5.1. Models Validation. It can be seen that, as a whole, the standard errors and maximum absolute errors of the calculation results increase slowly with the temperature range's width on the left surface of wall. The standard errors of the effective heat capacity model (Eff) and enthalpy model (Ent) are lower than $1.4^{\circ} \mathrm{C}$ and $1.7^{\circ} \mathrm{C}$, and the maximum absolute errors are lower than $2.8^{\circ} \mathrm{C}$ and $3.6^{\circ} \mathrm{C}$, respectively. The maximum errors always exist for the calculation results of the left surface. The reason for this is that the decrement effect of wall makes the temperature fluctuation on the right surface be significantly lower than that on the left surface; as a result, the calculation errors on the right surface reduce, while the temperature on the left surface is slightly influenced by the wall, which makes the errors be relatively larger. Figures $6(\mathrm{l})$ and $6(\mathrm{~m})$ are the calculation errors of the temperature on the two surfaces of PCM layer in Block 3 wall. It can be seen from the data in Table 3 that the standard errors of the two models are both lower than $2.9^{\circ} \mathrm{C}$ and mostly in the range from $1.0^{\circ} \mathrm{C}$ to $2.5^{\circ} \mathrm{C}$; the standard errors of the effective heat capacity model (Eff) are lower than that of the enthalpy model (Ent). The errors are produced by these factors: (1) in the experiment, it is impossible to reach the absolute adiabatic condition around the walls, but in the mathematical models, it is the idealized adiabatic condition around the walls; (2) the error inevitably exists in the obtained experimental data; (3) to control the calculation amount, the size of the computational mesh is set as $0.005 \mathrm{~m} \times 0.005 \mathrm{~m}$, so the calculation result is the average value of the area of each mesh; and (4) not all the assumptions in the models and the conditions in the experiment are unified. In spite of these, there is reasonable agreement between the curves of the calculation results and experiment data (the error is lower than 5\%); therefore, it is considered that the results of the two models can both meet the requirement for the analysis, and the effective heat capacity model is more accurate than the enthalpy model.

3.5.2. Experimental Analysis. Seen from Figures 4-7 that, for the four experiments under the common boundary temperature ranges (from temperature range 1 to temperature range 4) of each wall, the temperature decrements, decrement factors, and time lags of the block walls with PCM (Block walls 2, 3, and 4) are all significantly larger than that of the block wall without PCM (Block wall 1). The increased amounts of the temperature decrements of Block walls 2, 3, and 4 are from $1.5^{\circ} \mathrm{C}$ to $5.0^{\circ} \mathrm{C}$, and the increased decrement factors are from 1.0 to 2.5 and those for the time lags are from $0.5 \mathrm{~h}$ to $3.0 \mathrm{~h}$, compared to Block wall 1 . This demonstrates that the phase transition energy storage effect has worked by the use of PCM, which plays an important role on the development of the unsteady-state thermal performance of wall.

Also, the decrement factors and time lags of each wall vary with a slowly declining trend on the whole with increasing width of boundary temperature ranges. The main reasons for this phenomenon can be explained as (1) for the air layers in the blocks, the width addition of the boundary temperature ranges increases the temperature difference between 
TABLE 3: Temperature decrements, decrement factors, time lags, standard errors, and maximum absolute errors of each block wall.

\begin{tabular}{|c|c|c|c|c|c|c|c|}
\hline \multirow[b]{2}{*}{ Indexes } & \multirow{2}{*}{$\begin{array}{l}\text { Temperature } \\
\text { decrements } \\
\left({ }^{\circ} \mathrm{C}\right)\end{array}$} & \multirow{2}{*}{$\begin{array}{l}\text { Decrement } \\
\text { factors }\end{array}$} & \multirow{2}{*}{$\begin{array}{c}\text { Time lags } \\
\text { (h) }\end{array}$} & \multicolumn{2}{|c|}{ Standard errors $\left({ }^{\circ} \mathrm{C}\right)$} & \multicolumn{2}{|c|}{ Maximum absolute errors $\left({ }^{\circ} \mathrm{C}\right)$} \\
\hline & & & & $\begin{array}{c}\text { Left surface } \\
\text { Eff/Ent }\end{array}$ & $\begin{array}{c}\text { Right surface } \\
\text { Eff/Ent }\end{array}$ & $\begin{array}{l}\text { Left surface } \\
\text { Eff/Ent }\end{array}$ & $\begin{array}{l}\text { Right surface } \\
\text { Eff/Ent }\end{array}$ \\
\hline Block walls and temperature ranges & \multicolumn{7}{|c|}{ Experimental values } \\
\hline \multicolumn{8}{|l|}{ Block 1 wall } \\
\hline Temperature range 1 & 17.5 & 4.02 & 6.17 & 0.50 & 0.28 & 0.90 & 0.54 \\
\hline Temperature range 2 & 49.9 & 4.10 & 5.42 & 0.62 & 0.69 & 1.29 & 1.23 \\
\hline Temperature range 3 & 51.6 & 4.07 & 5.58 & 0.60 & 0.72 & 1.14 & 1.38 \\
\hline Temperature range 4 & 61.0 & 3.85 & 5.17 & 1.04 & 0.77 & 1.79 & 1.25 \\
\hline \multicolumn{8}{|l|}{ Block 2 wall } \\
\hline Temperature range 1 & 19.0 & 5.30 & 7.25 & $0.62 / 0.76$ & $0.24 / 0.27$ & $0.83 / 1.40$ & $0.46 / 0.48$ \\
\hline Temperature range 2 & 51.2 & 5.43 & 6.17 & $0.36 / 0.33$ & $0.67 / 0.47$ & $0.72 / 2.64$ & $1.25 / 0.99$ \\
\hline Temperature range 3 & 51.5 & 5.17 & 6.08 & $0.63 / 1.41$ & $0.60 / 0.46$ & $0.98 / 2.91$ & $1.02 / 0.87$ \\
\hline Temperature range 4 & 65.4 & 5.18 & 5.92 & $0.52 / 1.69$ & $0.70 / 0.63$ & $1.12 / 3.52$ & $1.34 / 1.46$ \\
\hline Temperature range 5 & 6.0 & 5.47 & 7.33 & $0.19 / 0.13$ & $0.12 / 0.16$ & $0.39 / 0.32$ & $0.20 / 0.26$ \\
\hline Temperature range 6 & 10.9 & 5.65 & 6.92 & $0.24 / 0.39$ & $0.19 / 0.28$ & $0.54 / 0.76$ & $0.37 / 0.48$ \\
\hline Temperature range 7 & 15.9 & 5.62 & 6.50 & $0.44 / 0.30$ & $0.24 / 0.26$ & $0.78 / 0.55$ & $0.45 / 0.49$ \\
\hline Temperature range 8 & 20.7 & 5.72 & 7.25 & $0.56 / 0.68$ & $0.31 / 0.37$ & $1.18 / 1.07$ & $0.55 / 0.62$ \\
\hline \multicolumn{8}{|l|}{ Block 3 wall } \\
\hline Temperature range 1 & 19.7 & 6.82 & 7.67 & $0.09 / 0.13$ & $0.24 / 0.30$ & $0.19 / 0.28$ & $0.45 / 0.53$ \\
\hline Temperature range 2 & 53.0 & 6.47 & 7.17 & $0.70 / 0.98$ & $0.77 / 0.44$ & $1.42 / 1.80$ & $1.10 / 0.99$ \\
\hline Temperature range 3 & 56.2 & 6.43 & 6.83 & $0.72 / 0.85$ & $0.70 / 0.50$ & $1.47 / 1.63$ & $1.24 / 1.05$ \\
\hline Temperature range 4 & 67.2 & 5.63 & 5.08 & $0.71 / 0.99$ & $0.94 / 1.43$ & $1.60 / 2.03$ & $2.18 / 3.15$ \\
\hline Temperature range 5 & 20.5 & 6.61 & 6.67 & $0.40 / 0.44$ & $0.20 / 0.25$ & $0.66 / 0.71$ & $0.40 / 0.45$ \\
\hline Temperature range 6 & 30.4 & 6.24 & 5.92 & $0.80 / 0.97$ & $0.34 / 0.47$ & $1.18 / 1.46$ & $0.68 / 0.86$ \\
\hline Temperature range 7 & 40.3 & 6.14 & 5.5 & $0.78 / 1.00$ & $0.47 / 0.66$ & $1.24 / 1.71$ & $1.01 / 1.21$ \\
\hline Temperature range 8 & 49.3 & 5.96 & 5.75 & $0.73 / 1.01$ & $0.62 / 0.93$ & $1.20 / 1.78$ & $1.37 / 1.55$ \\
\hline \multicolumn{8}{|l|}{ PCM in the holes of Block 3 wall } \\
\hline Temperature range 1 & - & - & - & $1.73 / 2.18$ & $1.29 / 1.88$ & $3.30 / 3.13$ & $2.34 / 2.66$ \\
\hline Temperature range 2 & - & - & - & $2.20 / 2.91$ & $1.58 / 2.25$ & $4.82 / 4.18$ & $3.43 / 4.52$ \\
\hline Temperature range 3 & - & - & - & $2.22 / 2.25$ & $1.74 / 1.50$ & $4.96 / 3.61$ & $3.76 / 2.92$ \\
\hline Temperature range 4 & - & - & - & $2.57 / 2.89$ & $2.23 / 2.27$ & $5.30 / 4.25$ & $4.18 / 5.47$ \\
\hline Temperature range 5 & - & - & - & $1.44 / 1.94$ & $0.99 / 1.50$ & $2.81 / 2.72$ & $1.96 / 1.78$ \\
\hline Temperature range 6 & - & - & - & $1.73 / 2.10$ & $1.04 / 1.57$ & $3.44 / 3.44$ & $2.25 / 2.10$ \\
\hline Temperature range 7 & - & - & - & $1.66 / 2.52$ & $1.17 / 1.71$ & $3.47 / 4.03$ & $2.39 / 2.83$ \\
\hline Temperature range 8 & - & - & - & $1.73 / 2.74$ & $1.34 / 1.99$ & $3.74 / 4.50$ & $2.58 / 3.75$ \\
\hline \multicolumn{8}{|l|}{ Block 4 wall } \\
\hline Temperature range 1 & 19.3 & 5.71 & 6.33 & $0.49 / 0.59$ & $0.25 / 0.32$ & $1.01 / 1.13$ & $0.45 / 0.72$ \\
\hline Temperature range 2 & 49.8 & 5.45 & 6.33 & $1.32 / 1.38$ & $0.54 / 0.35$ & $2.42 / 2.64$ & $1.13 / 0.61$ \\
\hline Temperature range 3 & 56.1 & 5.96 & 6.33 & $1.31 / 1.26$ & $0.65 / 0.26$ & $2.50 / 2.50$ & $1.24 / 0.71$ \\
\hline Temperature range 4 & 62.7 & 4.87 & 5.92 & $1.37 / 1.43$ & $0.50 / 0.45$ & $2.75 / 3.04$ & $1.05 / 0.98$ \\
\hline Temperature range 5 & 19.9 & 5.45 & 5.83 & $0.52 / 0.49$ & $0.22 / 0.40$ & $0.94 / 0.83$ & $0.34 / 0.69$ \\
\hline Temperature range 6 & 29.5 & 5.41 & 5.67 & $0.54 / 0.59$ & $0.38 / 0.58$ & $1.01 / 1.03$ & $0.64 / 1.01$ \\
\hline Temperature range 7 & 34.8 & 5.10 & 5.67 & $0.62 / 0.72$ & $0.44 / 0.92$ & $1.17 / 1.25$ & $0.74 / 1.74$ \\
\hline Temperature range 8 & 38.8 & 5.12 & 6.08 & $0.70 / 0.78$ & $0.36 / 0.62$ & $1.34 / 1.43$ & $0.69 / 1.32$ \\
\hline
\end{tabular}



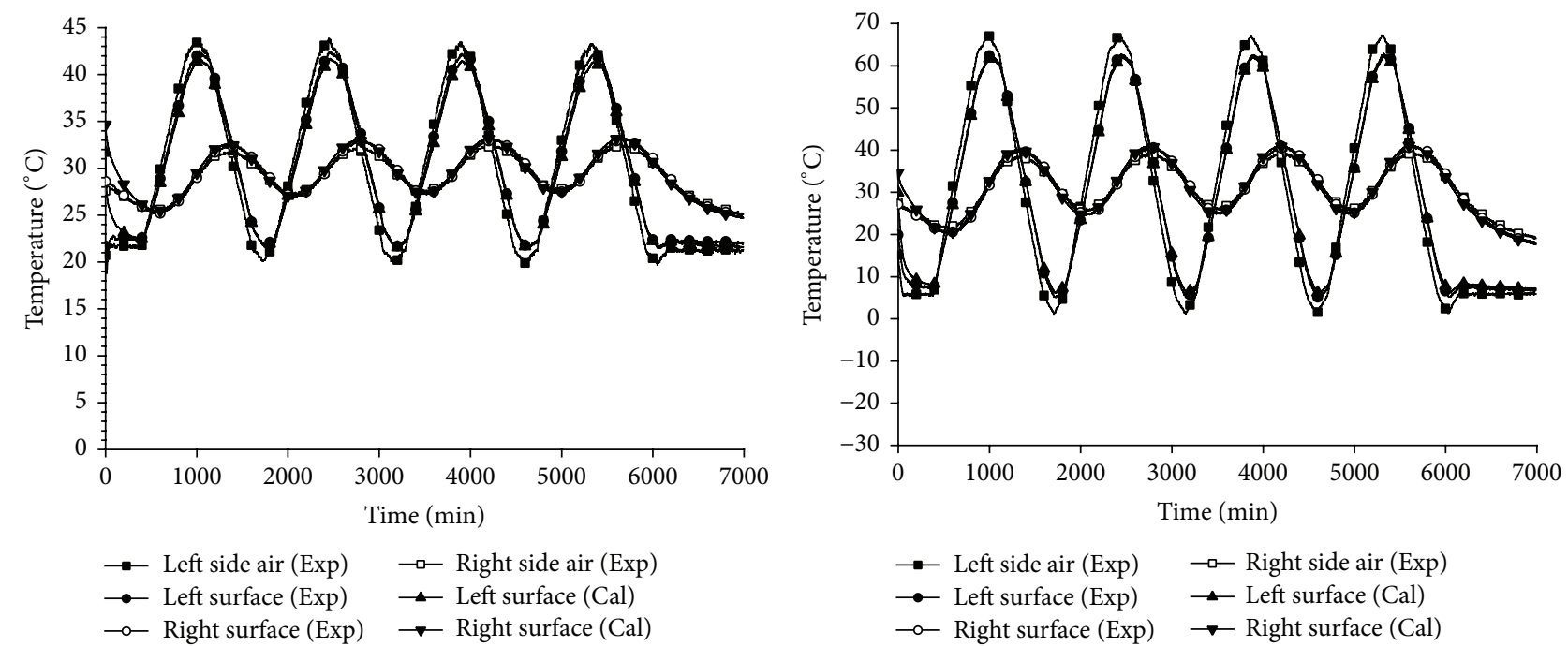

(a) Temperature range 1

(b) Temperature range 2
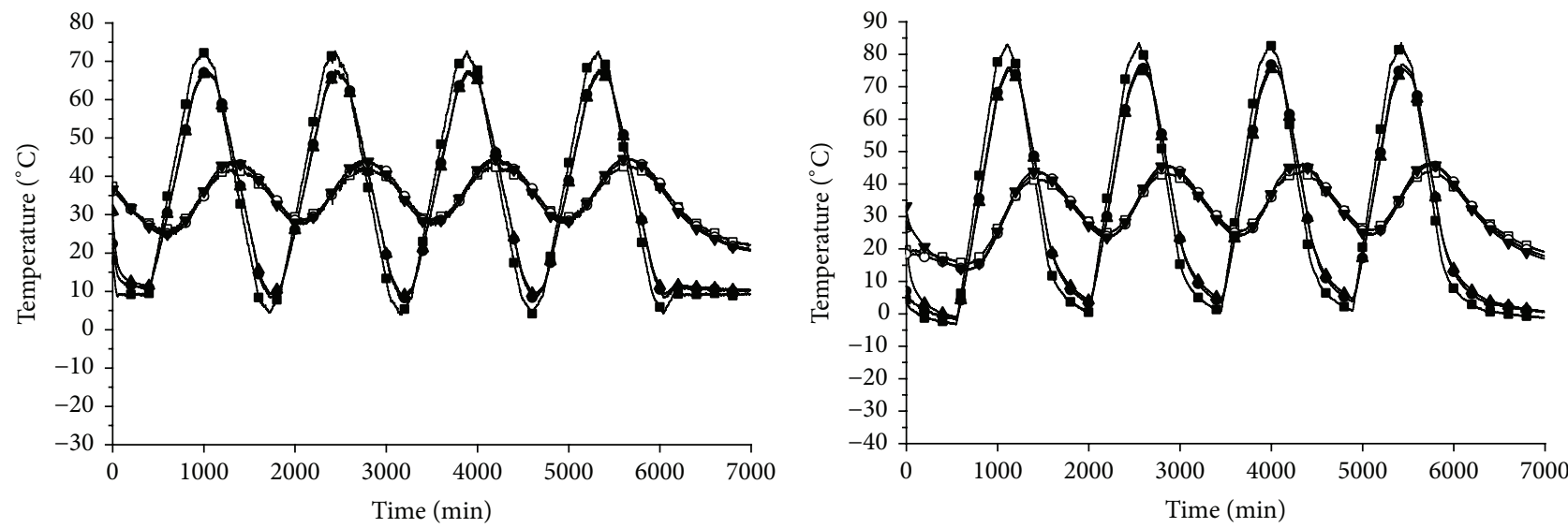

$\rightarrow$ Left side air (Exp) $\quad \rightarrow$ Right side air (Exp)
$\rightarrow-$ Left surface (Exp) $\quad \longrightarrow$ Left surface (Cal)
$\multimap-$ Right surface (Exp) $\quad \longrightarrow$ Right surface (Cal)

$\rightarrow-$ Left side air (Exp) $\quad \rightarrow$ Right side air (Exp)

$\rightarrow$ Left surface (Exp) $\rightarrow$ Left surface (Cal)

$\multimap$ Right surface (Exp) $\rightarrow$ Right surface (Cal)

(c) Temperature range 3

(d) Temperature range 4

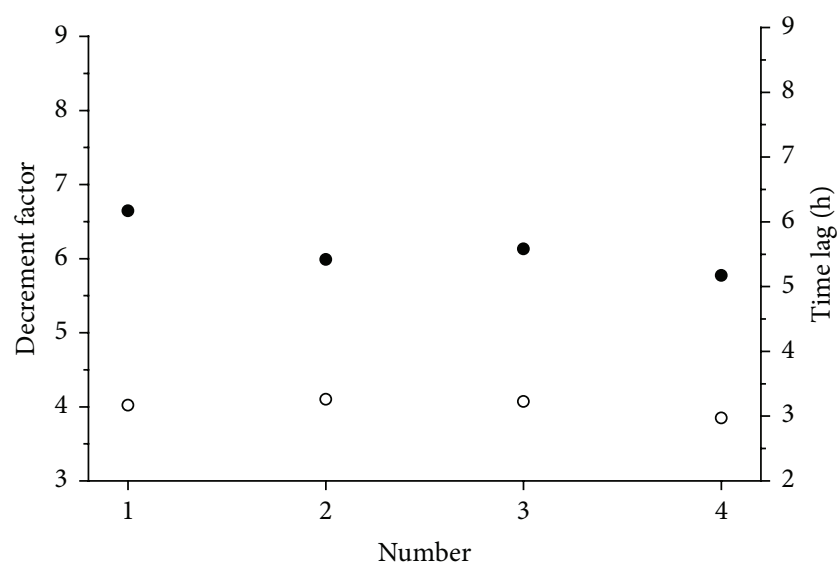

- Decrement factor

- Time lag

(e) Decrement factors and time lags

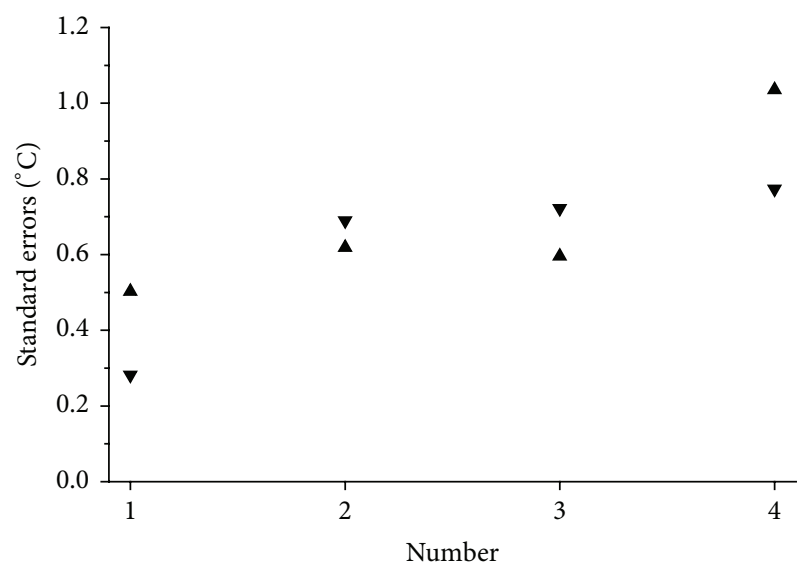

- Left surface

v Right surface

(f) Standard errors

Figure 4: Continued. 


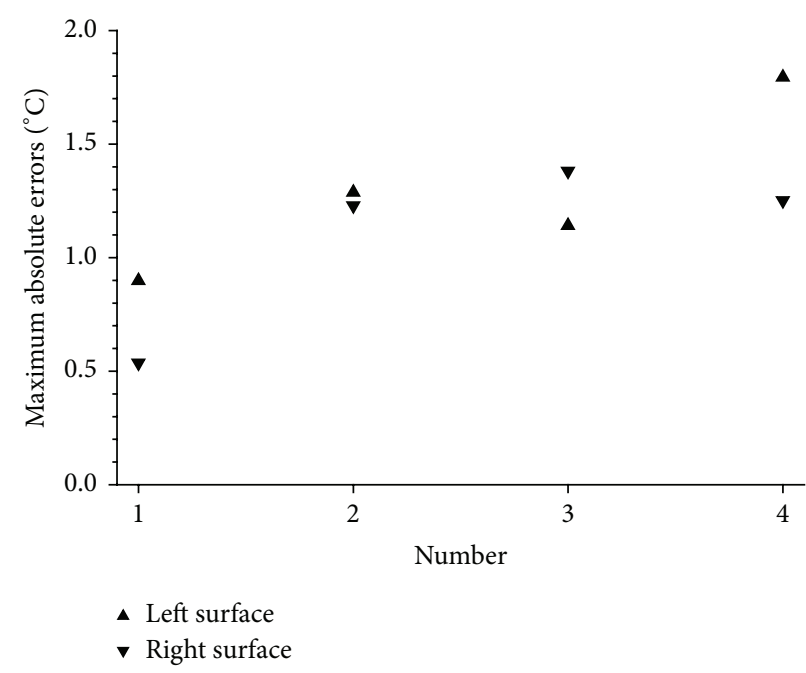

(g) Maximum absolute errors

FIGURE 4: Experimental data of Block 1 wall and calculation errors.

the colder surface and the hotter surface to some extent, which enhances the heat convection and radiation in the holes and makes the thermal performance of wall reduce, and consequently produces the fall of the decrement factors and time lags; (2) for the blocks with PCM, when the temperature of the PCM in the wall has not exceeded the phase transition temperature range (the phase transition of PCM has not totally finished), the PCM wall can reach high unsteady-state thermal performance (Figures 6(a) and 6(e)), but once the temperature of the PCM has exceeded it, as shown in Table 1 (it is apparent in Figures 6(b), 6(c), 6(d), 6(f), 6(g), and 6(h)), the phase transition process has been totally finished: namely, the latent heat of PCM has been used up, and only the sensible heat of the liquid or solid PCM can store the heat; because the sensible heat of PCM is at least one order of magnitude lower than the latent heat, the thermal performance of wall greatly reduce after the phase transition has finished, and the function of PCM gradually reduces with the increased width of the boundary temperature range, which makes the decrement factors and time lags of wall decrease. Under the common boundary temperature ranges (from temperature range 1 to temperature range 4 ), the temperature decrements, decrement factors, and time lags between Block wall 2 and Block wall 4 have little difference.

For the additional boundary temperature ranges (from temperature range 5 to temperature range 8 ) of Block walls 2,3 , and 4 , the decrement factors and time lags of Block 2 wall are slightly larger than that of Block 4 wall, but the temperature decrements of Block 4 wall are greatly larger than that of Block 2 wall. This phenomenon results from the large difference of the boundary temperature ranges between the two walls: the boundary temperature ranges of Block 4 wall are larger; therefore, in spite of its smaller decrement factors and time lags compared to Block 2 wall, the temperature decrements are large; it should not be simply considered that the thermal performance of Block 4 wall is lower than Block 2 wall. Hence, the decrement factor and the temperature decrement should be both considered as the indexes for evaluating the unsteady-state thermal performance of PCM wall.

For the data of Block 3 wall, under the common boundary temperature ranges (from temperature range 1 to temperature range 4), its temperature decrements, decrement factors, and time lags are higher than Block 2 wall and Block 4 wall with the values of $0^{\circ} \mathrm{C}-5^{\circ} \mathrm{C}, 0.5-1.5$, and $0 \mathrm{~h}-2.5 \mathrm{~h}$, respectively; under the additional boundary temperature ranges (from temperature range 5 to temperature range 8), its unsteadystate thermal performance also apparently improves. It is worthy to point out that, although the mass of the PCM filled into each block is not changed, the thermal performance of Block 3 wall is higher than Block 4 wall under the same boundary condition. The reasons are complicated: one of the important reasons is that the addition of a certain amount of gypsum takes the place of a part of air, which increases the heat capacity and consequently enhances the unsteady-state thermal performance of the Block 3 wall.

It can be concluded from the experimental data that suitable environmental condition for the application of the PCM wall with a certain structure exists; for different boundary temperature conditions, the different optimum structure of PCM wall should be selected; the unsteady-state thermal performance of PCM wall under different environmental conditions is related to the factors such as phase transition temperature, latent heat, PCM's thickness, and position in the wall.

\section{Conclusions}

In this paper, a type of concrete hollow blocks with typical structure and a common used phase change material (PCM) were adopted, and the PCM was filled into different positions of the hollow blocks, and then different types of composite PCM hollow blocks were produced. The temperaturechanging hot chamber method was used to test the thermal 


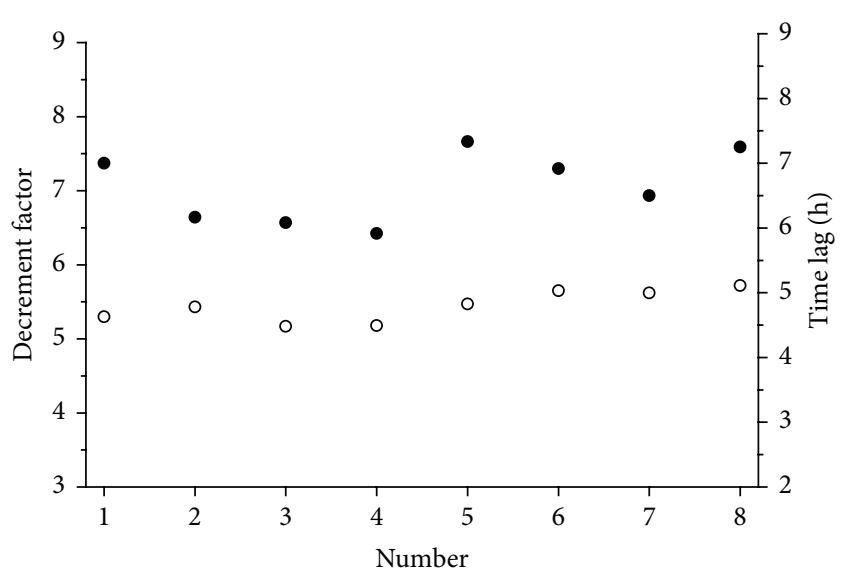

- Decrement factor - Time lag

(a) Decrement factors and time lags

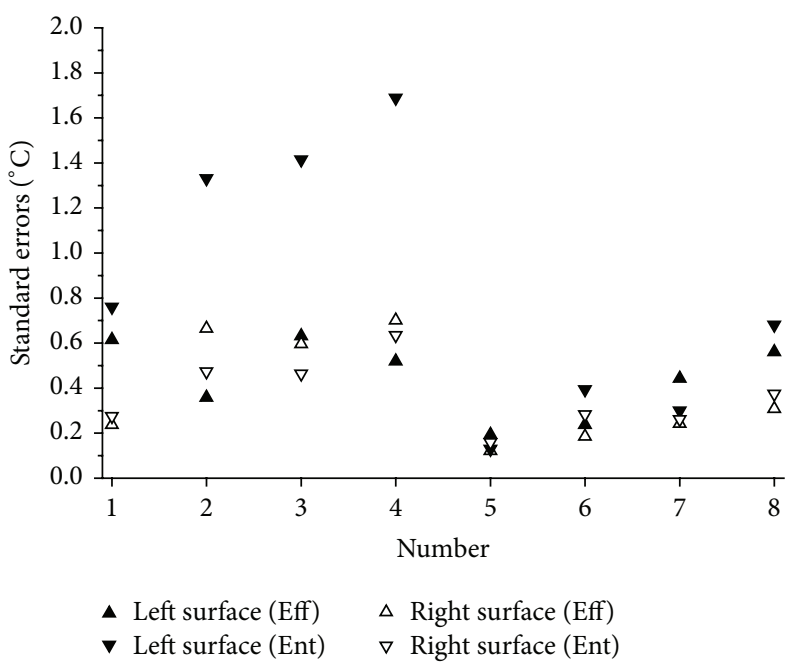

(b) Standard errors

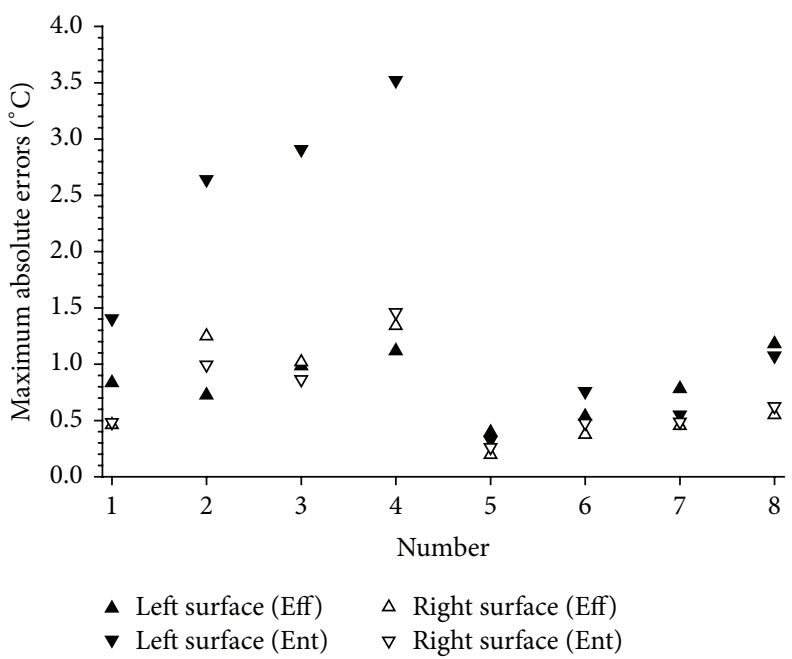

(c) Maximum absolute errors

Figure 5: Experimental data of Block 2 wall and calculation errors.

performance of the hollow block walls with and without PCM under different temperature conditions; meanwhile, the enthalpy model and effective heat capacity model were used to calculate the phase transition heat transfer process under the conditions of experiments. The results of the models were validated by the experimental data, the thermal performances of different hollow block walls were compared, and the reasons for the difference on the thermal performance of each wall were analyzed, which provide the data reference and guide for the engineering application of the composite PCM hollow block wall. After the analysis of this research, it can be concluded that

(1) for the dynamic heat transfer processes of the composite PCM hollow block walls with multiple structures, the calculation results of the adopted two-dimensional enthalpy model and effective heat capacity model have reasonable agreement with the experimental data (the errors are lower than 5\%); therefore, it is considered that the two mathematical models can both satisfy the analysis requirement on the problem of the unsteady-state phase transition heat transfer, and the effective heat capacity model is more accurate than the enthalpy model;

(2) when the phase transition temperature of the PCM in the wall is within the temperature range of the environment, the unsteady-state thermal performance of the hollow block wall with PCM is higher than that of the same wall without PCM (in the research of this paper, the increased amounts of the temperature decrements of the PCM wall are from $1.5^{\circ} \mathrm{C}$ to $5.0^{\circ} \mathrm{C}$, and the increased decrement factors are from 1.0 to 2.5 and those for the time lags are from $0.5 \mathrm{~h}$ to $3.0 \mathrm{~h}$ );

(3) when the temperature of the PCM in the wall has not exceeded the phase transition temperature range, 

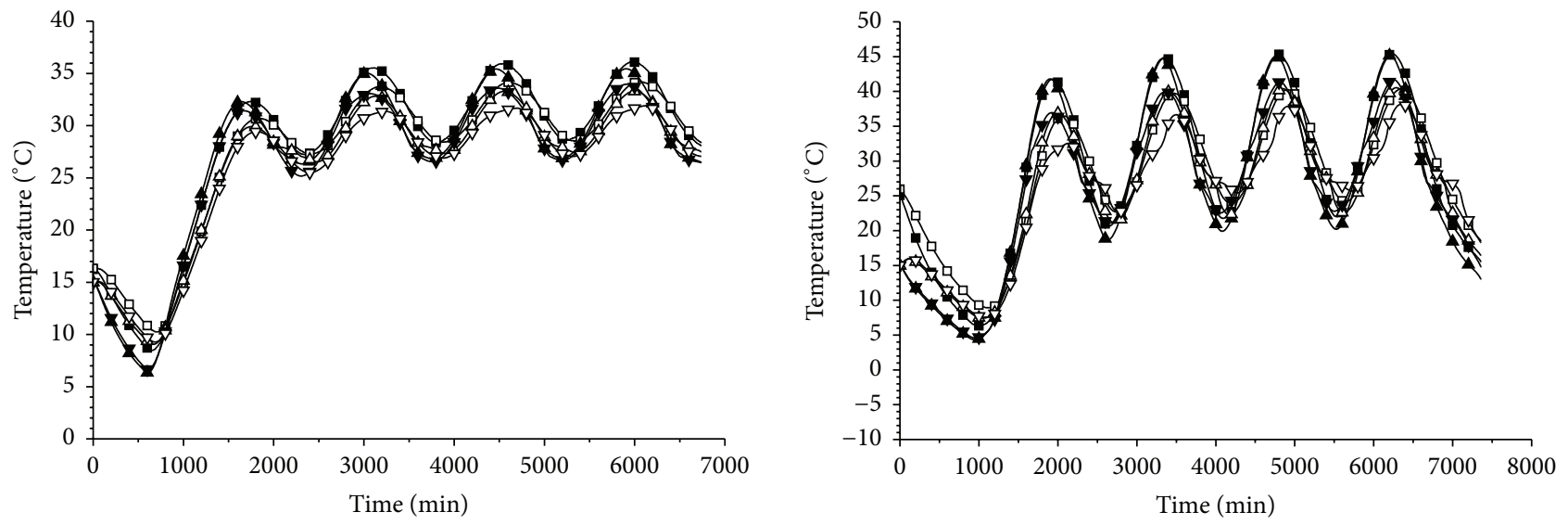

- Left surface of PCM (Exp) $\quad \longrightarrow$ - Right surface of PCM (Exp)

$\neg$ Left surface of PCM (Eff) $\quad \triangle$ Right surface of PCM (Eff)

$\rightarrow-$ Left surface of PCM (Exp) $\quad \longrightarrow$ - Right surface of PCM (Exp)

$\rightarrow$ Left surface of PCM (Eff) $\rightarrow-$ Right surface of PCM (Eff)

$\rightarrow$ Left surface of PCM (Ent) $\rightarrow$ Right surface of PCM (Ent)

(a) Surfaces of PCM (temperature range 1)
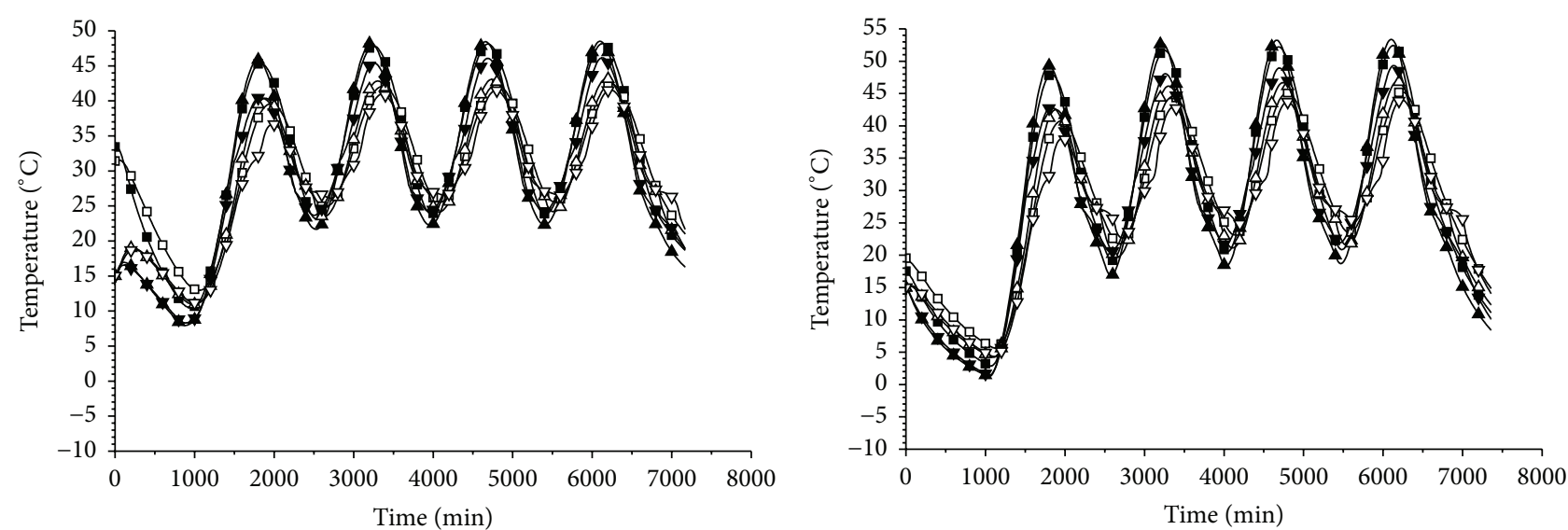

$\rightarrow-$ Left surface of PCM (Exp) $\quad \longrightarrow$ - Right surface of PCM (Exp)

$\triangle$ Left surface of PCM (Eff) $\triangle-$ Right surface of PCM (Eff)

$\rightarrow$ Left surface of PCM (Ent) $\rightarrow-$ Right surface of PCM (Ent)

(c) Surfaces of PCM (temperature range 3)
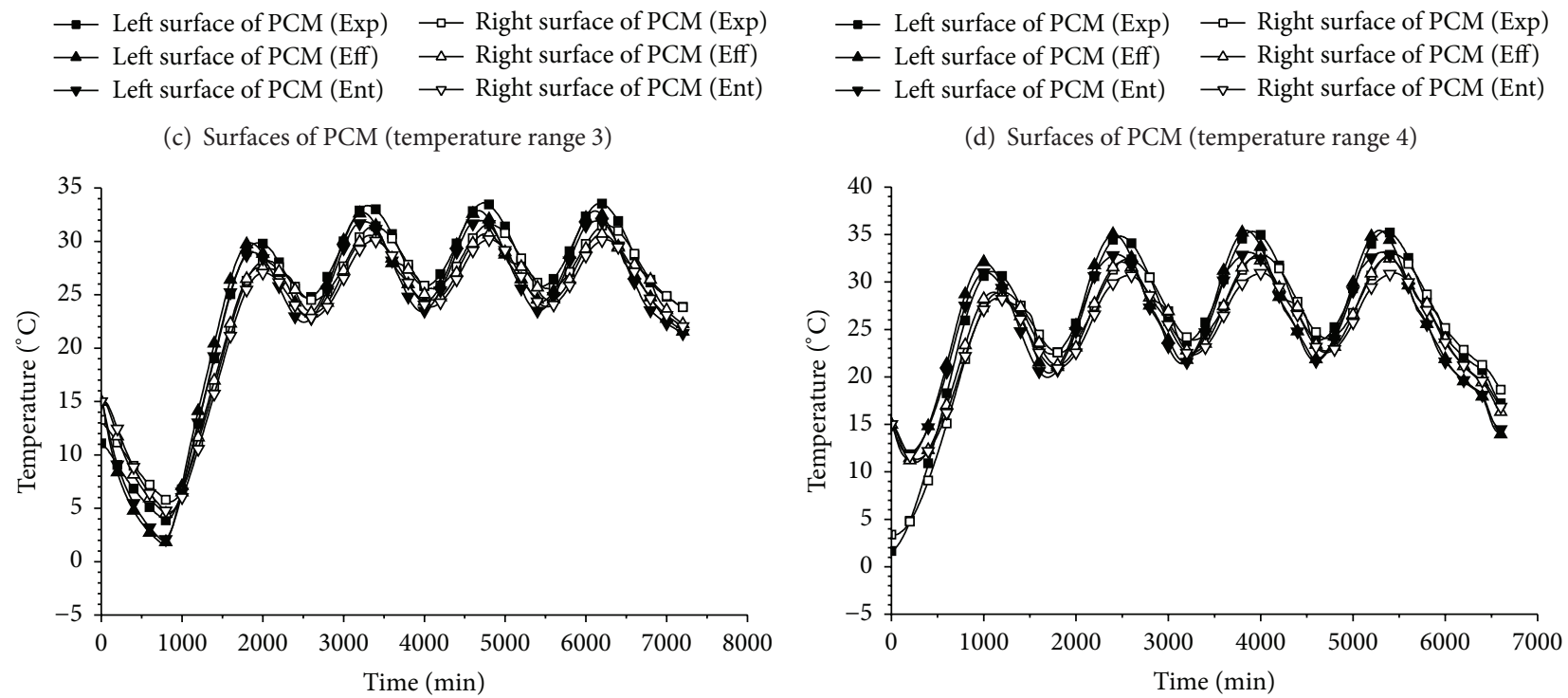

(d) Surfaces of PCM (temperature range 4)

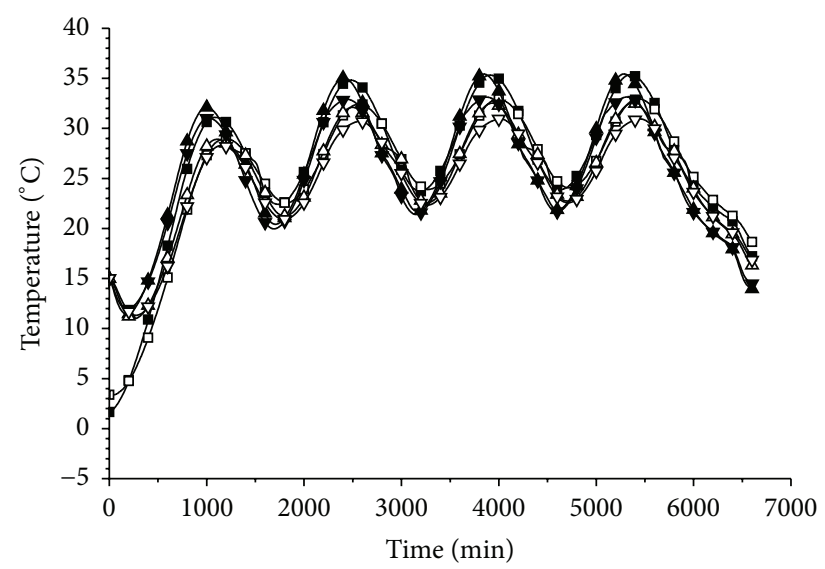

$\begin{array}{ll}\rightarrow \text { Left surface of PCM (Exp) } & \rightarrow-\text { Right surface of PCM (Exp) } \\ \rightarrow \text { Left surface of PCM (Eff) } & \rightarrow-\text { Right surface of PCM (Eff) } \\ \rightarrow \text { Left surface of PCM (Ent) } & \rightarrow-\text { Right surface of PCM (Ent) }\end{array}$

(e) Surfaces of PCM (temperature range 5)

$\begin{array}{ll}\rightarrow \text { Left surface of PCM (Exp) } & \rightarrow-\text { Right surface of PCM (Exp) } \\ \rightarrow \text { Left surface of PCM (Eff) } & \rightarrow-\text { Right surface of PCM (Eff) } \\ \rightarrow-\text { Left surface of PCM (Ent) } & \rightarrow-\text { Right surface of PCM (Ent) }\end{array}$

(f) Surfaces of PCM (temperature range 6)

FIgUre 6: Continued. 


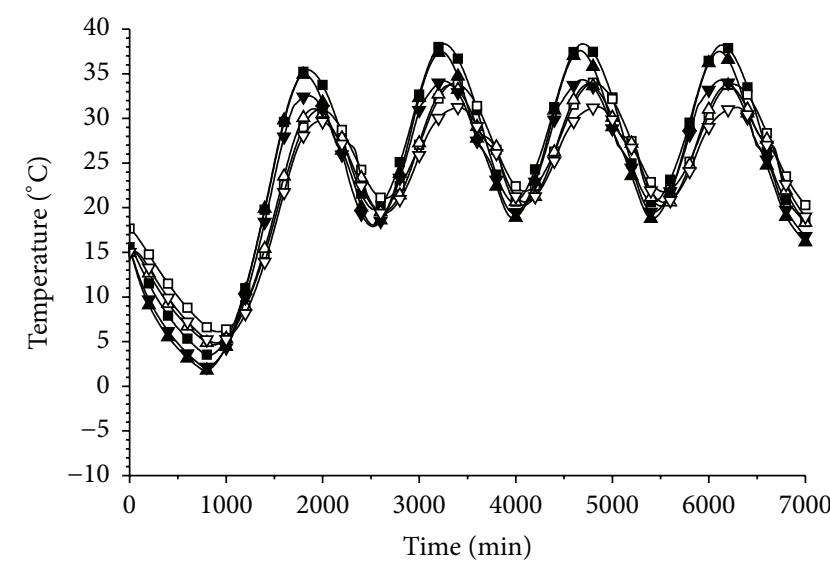

$\rightarrow$ Left surface of PCM (Exp) $\quad \longrightarrow$ Right surface of PCM (Exp)

$\_$Left surface of PCM (Eff) $\rightarrow$ Right surface of PCM (Eff)

$\rightarrow$ Left surface of PCM (Ent) $\rightarrow-$ Right surface of PCM (Ent)

(g) Surfaces of PCM (temperature range 7)

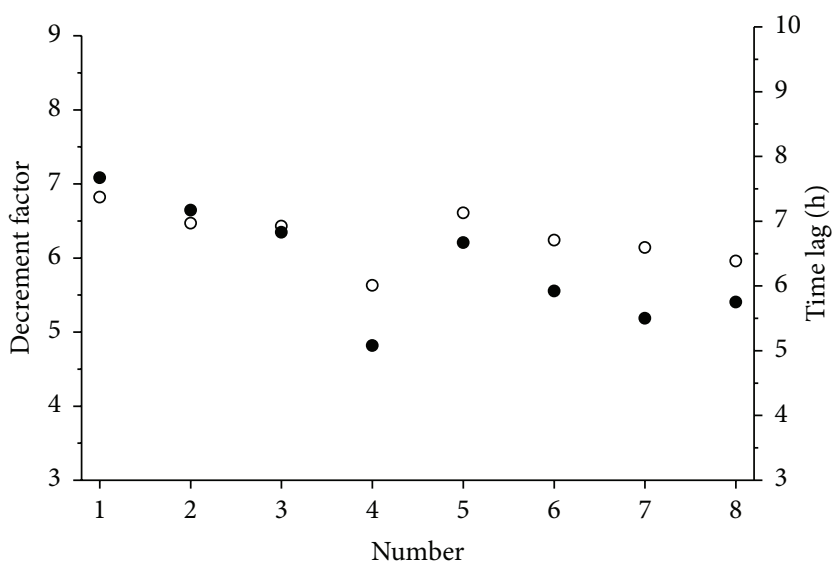

- Decrement factor

- Time lag

(i) Decrement factors and time lags

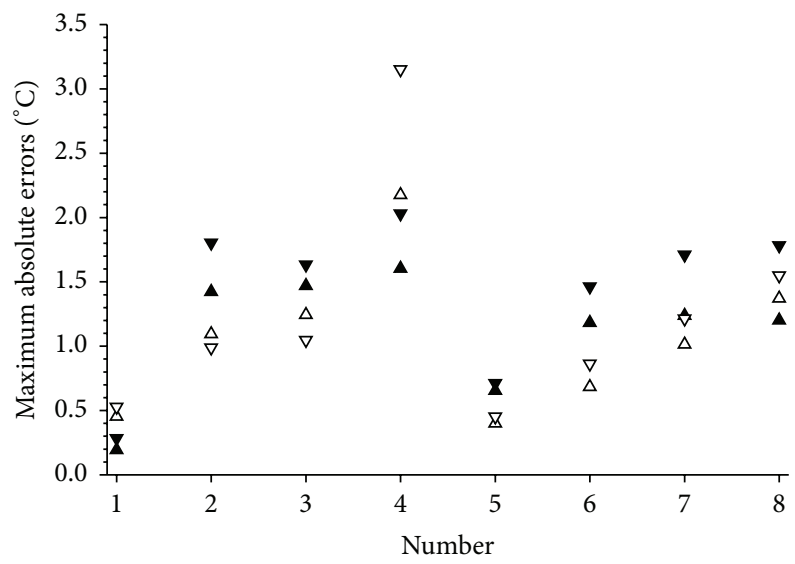

- Left surface (Eff) $\Delta$ Right surface (Eff)

$\nabla$ Left surface (Ent) $\quad \nabla$ Right surface (Ent)

(k) Maximum absolute errors

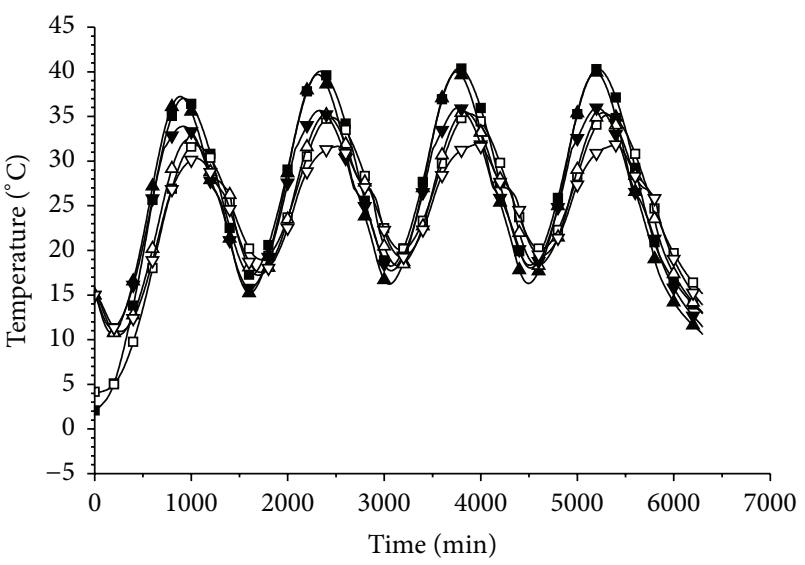

- Left surface of PCM (Exp) $\rightarrow$ Right surface of PCM (Exp)

$\_$Left surface of PCM (Eff) $\rightarrow$ Right surface of PCM (Eff)

$\neg$ Left surface of PCM (Ent) $\rightarrow-$ Right surface of PCM (Ent)

(h) Surfaces of PCM (temperature range 8)

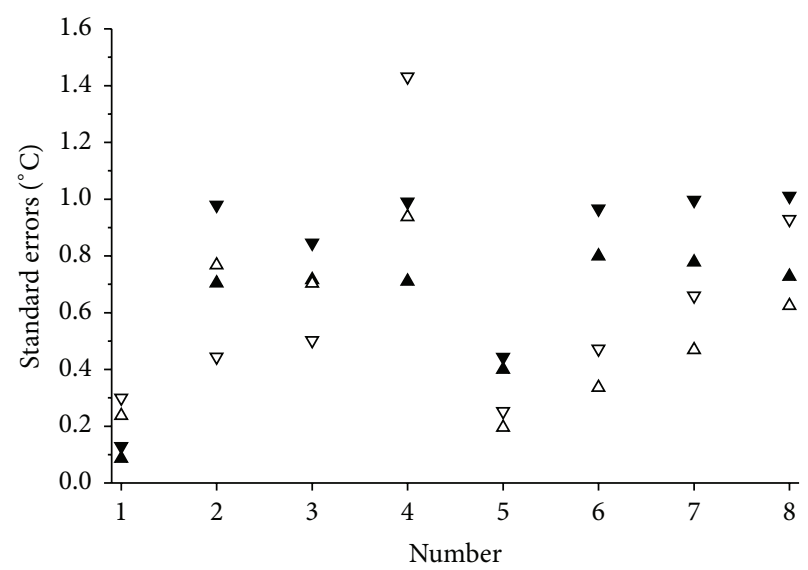

$\Delta$ Left surface (Eff) $\Delta$ Right surface (Eff)

- Left surface (Ent) $\quad \nabla$ Right surface (Ent)

(j) Standard errors

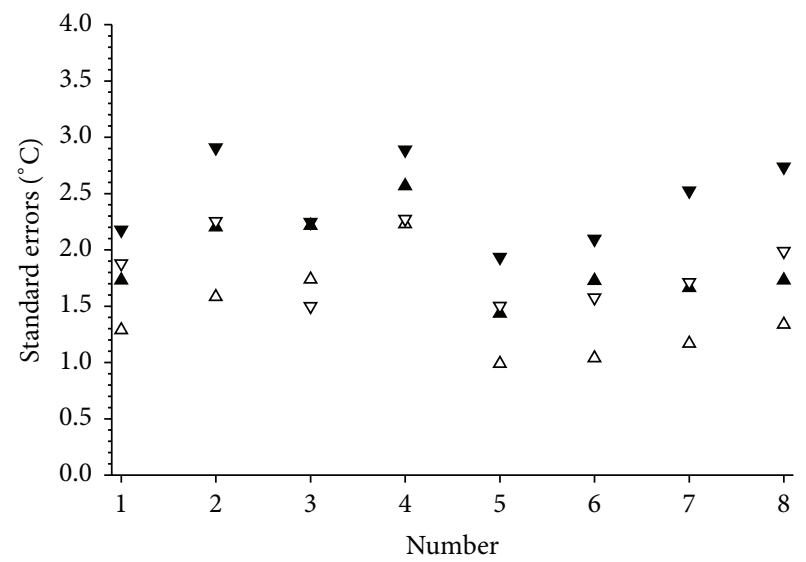

\ Left surface of PCM (Eff) $\Delta$ Right surface of PCM (Eff)

$\checkmark$ Left surface of PCM (Ent) $\quad \nabla$ Right surface of PCM (Ent)

(1) Standard errors on the surfaces of PCM

FIGURE 6: Continued. 


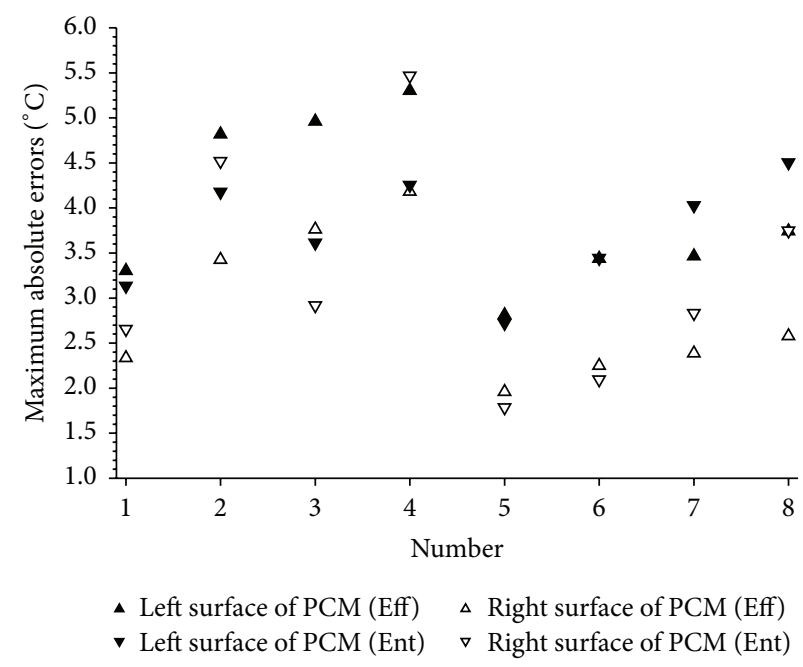

(m) Maximum absolute errors on the surfaces of PCM

Figure 6: Experimental data of Block 3 wall and calculation errors.

the PCM wall can reach high unsteady-state thermal performance; otherwise, the function of PCM will significantly reduce, which makes the unsteady-state thermal performance of wall reduce;

(4) the temperature decrement, decrement factor, and time lag should be considered together as the indexes for evaluating the unsteady-state thermal performance of PCM wall; otherwise, the validity of the evaluation will probably be affected;

(5) optimum boundary condition exists for the PCM wall with a certain structure; for different boundary conditions, the PCM wall structure should be properly selected; the unsteady-state thermal performance of the PCM wall is related to the factors such as phase transition temperature, latent heat, thickness, and the position in the wall.

\section{Highlights}

(i) The two mathematical models for the phase transition calculation were validated.

(ii) The thermal performance of composite PCM hollow block walls was analyzed.

(iii) The impact factors on the thermal performance of PCM hollow block wall were analyzed.

(iv) The thermal performances of the wall with and without PCM were compared.

\section{Nomenclature}

c: $\quad$ Specific heat, $\mathrm{kJ} \cdot \mathrm{kg}^{-1} \cdot \mathrm{K}^{-1}$

$c_{\text {eff }}$ : Effective heat capacity of PCM, $\mathrm{kJ} \cdot \mathrm{kg}^{-1} \cdot \mathrm{K}^{-1}$

$c_{p \text {,equ }}$ : Equivalent specific heat of PCM in the phase transition temperature range, $\mathrm{kJ} \cdot \mathrm{kg}^{-1} \cdot \mathrm{K}^{-1}$

$c_{p, s}$ : Specific heat of the PCM in the solid state, $\mathrm{kJ} \cdot \mathrm{kg}^{-1} \cdot \mathrm{K}^{-1}$

$c_{p, l}: \quad$ Specific heat of the PCM in the liquid state, $\mathrm{kJ} \cdot \mathrm{kg}^{-1} \cdot \mathrm{K}^{-1}$

$f(\tau)$ : Heat flow function as a function of $\tau$, $\mathrm{W} \cdot \mathrm{m}^{-2}$

$H: \quad$ Enthalpy of PCM $\left(\mathrm{kJ} \cdot \mathrm{kg}^{-1}\right)$

$h_{a}$ : Convective heat transfer coefficient when $x=1, \mathrm{~W} \cdot \mathrm{m}^{-2} \cdot \mathrm{K}^{-1}$

$h_{b}$ : Convective heat transfer coefficient when $x=N_{x}, \mathrm{~W} \cdot \mathrm{m}^{-2} \cdot \mathrm{K}^{-1}$

$i$ : $\quad$ Sequence number of data

L: $\quad$ Latent heat of PCM, $\mathrm{kJ} \cdot \mathrm{kg}^{-1}$

$m$ : $\quad$ Mass of the PCM, kg

$n$ : $\quad$ Amount of data

$N_{i}: \quad i$ th datum

$N_{\text {sta }, i}: i$ th standard datum

$N_{x}$ : Total number of the meshes on the $x$ direction

$N_{y}$ : Total number of the meshes on the $y$ direction

T: $\quad$ Temperature, ${ }^{\circ} \mathrm{C}$

$T_{f a}$ : Boundary air temperature when $x=1,{ }^{\circ} \mathrm{C}$

$T_{f b}$ : Boundary air temperature when $x=N_{x}$, ${ }^{\circ} \mathrm{C}$

$T_{\text {init }}$ : Initial temperature, ${ }^{\circ} \mathrm{C}$

$T_{m}$ : Mean temperature of the phase transition temperature range, ${ }^{\circ} \mathrm{C}$ 

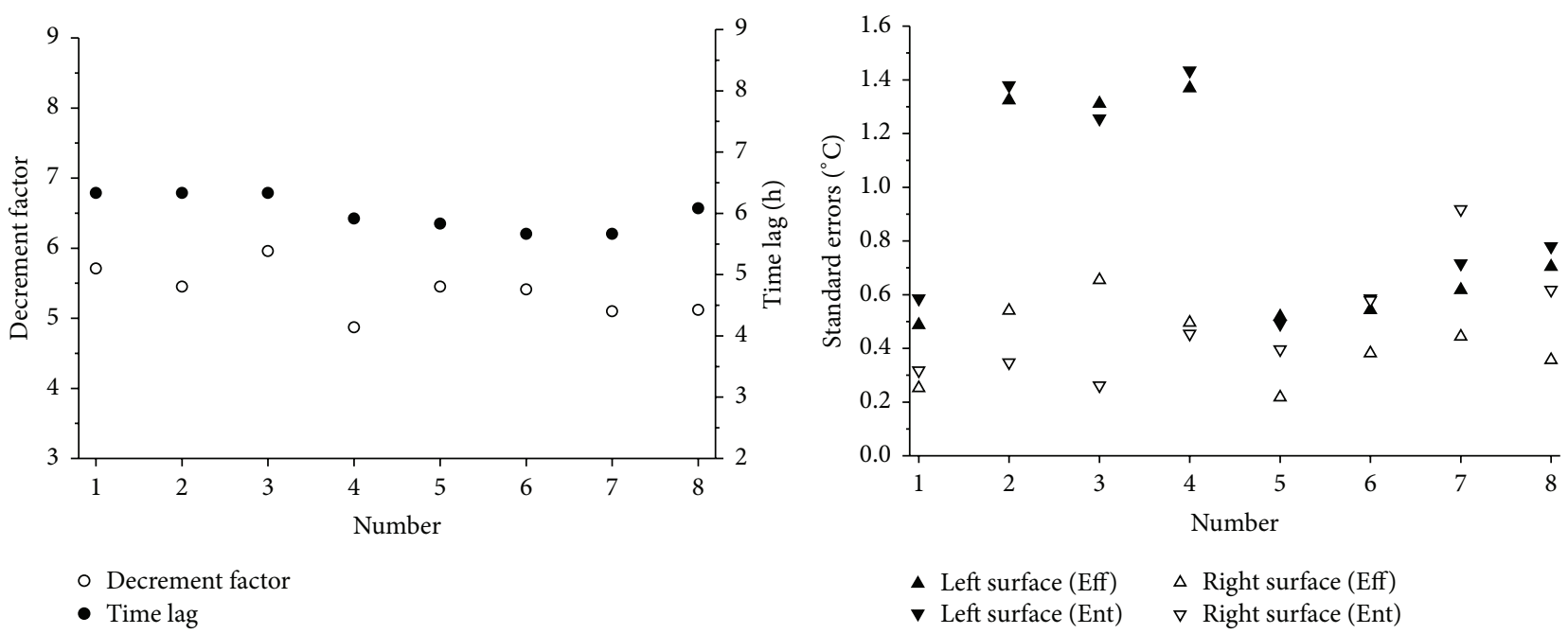

(a) Decrement factors and time lags

(b) Standard errors

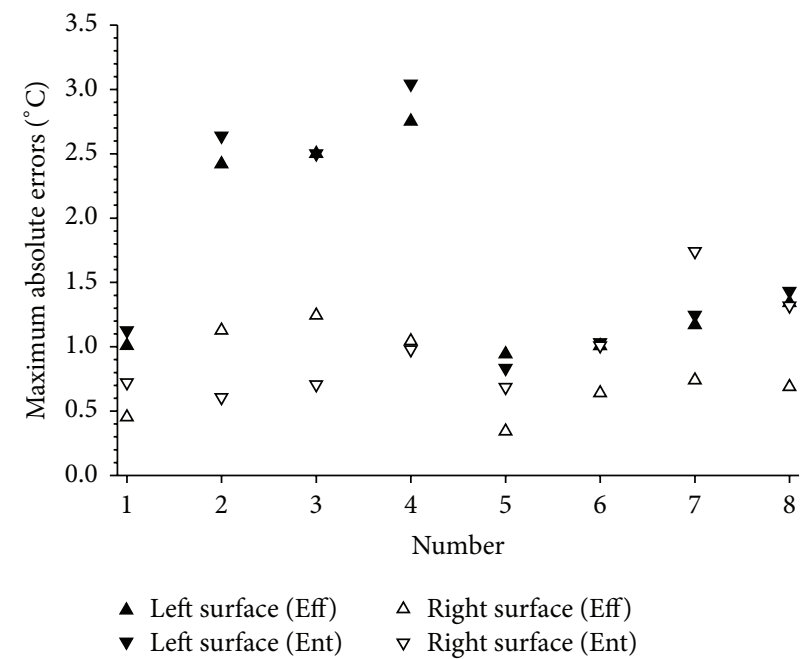

(c) Maximum absolute errors

FiguRE 7: Experimental data of Block 4 wall and calculation errors.

$T(x, y, \tau): \quad$ Temperature of the point $(x, y)$ at time point $\tau,{ }^{\circ} \mathrm{C}$

$T(x, y, \tau+1)$ : Temperature of the point $(x, y)$ at the time of $\tau+1,{ }^{\circ} \mathrm{C}$

$x: \quad$ Direction of thickness, $\mathrm{m}$

$y: \quad$ Direction of width, $\mathrm{m}$.

\section{Greek Symbols}

$\rho:$ Density, $\mathrm{kg} \cdot \mathrm{m}^{-3}$

$\tau$ : Time, $\mathrm{s}$

$\lambda$ : Thermal conductivity, $\mathrm{W} \cdot \mathrm{m}^{-1} \cdot \mathrm{K}^{-1}$

$\varepsilon$ : Half of the phase transition temperature range, ${ }^{\circ} \mathrm{C}$

$\sigma$ : Standard error, ${ }^{\circ} \mathrm{C}$

$\sigma^{\prime}$ : Maximum absolute error, ${ }^{\circ} \mathrm{C}$

\section{Subscripts}

$E$ : Point right to the point $p$ init: Initial

$N$ : Point above the point $p$

$N^{\prime}$ : Point above the point $p^{\prime}$

$p$ : Boundary meshes when $x=1$

$p^{\prime}$ : Boundary meshes when $x=N_{x}$

$S: \quad$ Point under the point $p$

$S^{\prime}$ : Point under the point $p^{\prime}$

sta: Standard

$W^{\prime}$ : Point left to the point $p^{\prime}$.

\section{Conflict of Interests}

The authors declare that there is no conflict of interests regarding the publication of this paper.

\section{Acknowledgments}

This work was financially supported by the Natural Science Foundation of China (no. 51508232), the Natural Science 
Foundation of Jiangsu Province (no. BK20150521), the Jiangsu Province Postdoctoral Science Foundation (no. 1501106B), and the Scientific Research Starting Foundation for Advanced Talents of Jiangsu University (no. 15JDG049).

\section{References}

[1] L. Aelenei, R. Pereira, H. Gonçalves, and A. Athienitis, "Thermal performance of a hybrid BIPV-PCM: modeling, design and experimental investigation," Energy Procedia, vol. 48, pp. 474483, 2014.

[2] M. Ahmed, O. Meade, and M. A. Medina, "Reducing heat transfer across the insulated walls of refrigerated truck trailers by the application of phase change materials," Energy Conversion and Management, vol. 51, no. 3, pp. 383-392, 2010.

[3] H. J. Alqallaf and E. M. Alawadhi, "Concrete roof with cylindrical holes containing PCM to reduce the heat gain," Energy and Buildings, vol. 61, pp. 73-80, 2013.

[4] A. Bontemps, M. Ahmad, K. Johanns, and H. Sallée, "Experimental and modelling study of twin cells with latent heat storage walls," Energy and Buildings, vol. 43, no. 9, pp. 2456-2461, 2011.

[5] A. M. Borreguero, M. Luz Sánchez, J. L. Valverde, M. Carmona, and J. F. Rodríguez, "Thermal testing and numerical simulation of gypsum wallboards incorporated with different PCMs content," Applied Energy, vol. 88, no. 3, pp. 930-937, 2011.

[6] L. F. Cabeza, C. Castellón, M. Nogués, M. Medrano, R. Leppers, and O. Zubillaga, "Use of microencapsulated PCM in concrete walls for energy savings," Energy and Buildings, vol. 39, no. 2, pp. 113-119, 2007.

[7] A. Castell, I. Martorell, M. Medrano, G. Pérez, and L. F. Cabeza, "Experimental study of using PCM in brick constructive solutions for passive cooling," Energy and Buildings, vol. 42, no. 4, pp. 534-540, 2010.

[8] H. Ye, H. He, X. Ge, and B. Xu, "Comparative numerical investigations on the melting process of form-stable phase change material using enthalpy formulation method and effective heat capacity formulation method," Acta Energiae Solaris Sinica, vol. 25, no. 4, pp. 488-491, 2004.

[9] COMSOL Multiphysics, COMSOL Multiphysics Engineering Simulation Software, COMSOL Multiphysics, Stockholm, Sweden, 2012.

[10] K. D. Antoniadis, M. J. Assael, C. A. Tsiglifisi, and S. K. Mylona, "Improving the design of greek hollow clay bricks," International Journal of Thermophysics, vol. 33, no. 12, pp. 22742290, 2012.

[11] K. Arendt, M. Krzaczek, and J. Florczuk, "Numerical analysis by FEM and analytical study of the dynamic thermal behavior of hollow bricks with different cavity concentration," International Journal of Thermal Sciences, vol. 50, no. 8, pp. 1543-1553, 2011.

[12] L. P. Li, Z. G. Wu, Y. L. He, G. Lauriat, and W. Q. Tao, "Optimization of the configuration of $290 \times 140 \times 90$ hollow clay bricks with 3-D numerical simulation by finite volume method," Energy and Buildings, vol. 40, no. 10, pp. 1790-1798, 2008.

[13] L. P. Li, Z. G. Wu, Z. Y. Li, Y. L. He, and W. Q. Tao, "Numerical thermal optimization of the configuration of multi-holed clay bricks used for constructing building walls by the finite volume method," International Journal of Heat and Mass Transfer, vol. 51, no. 13-14, pp. 3669-3682, 2008.

[14] M. S. El-Genk and C. Gao, "Transient heat conduction during quenching of downward facing copper and stainless steel convex surfaces," Numerical Heat Transfer Part A: Applications, vol. 29, no. 6, pp. 543-573, 1996.
[15] C. Gao, "Accuracy of the general Peaceman and Rachford alternating direction implicit method," International Communications in Heat and Mass Transfer, vol. 23, no. 8, pp. 1193-1199, 1996.

[16] C. Gao and Y. Wang, "A general formulation of peaceman and rachford ADI method for the $N$-dimensional heat diffusion equation," International Communications in Heat and Mass Transfer, vol. 23, no. 6, pp. 845-854, 1996.

[17] J. Mackerle, "Finite elements and boundary elements applied in phase change, solidification and melting problems. A bibliography (1996-1998)," Finite Elements in Analysis and Design, vol. 32, no. 3, pp. 203-211, 1999.

[18] A. Carbonari, M. De Grassi, C. Di Perna, and P. Principi, "Numerical and experimental analyses of PCM containing sandwich panels for prefabricated walls," Energy and Buildings, vol. 38, no. 5, pp. 472-483, 2006.

[19] Ministry of Housing and Urban-Rural Development of the People's Republic of China, Thermal Design Code for Civil Building (GB50176-93), China Planning Press, Beijing, China, 1993.

[20] Y. Zhang, K. Du, J. He, L. Yang, Y. Li, and S. Li, "Impact factors analysis on the thermal performance of hollow block wall," Energy and Buildings, vol. 75, pp. 330-341, 2014.

[21] S. V. Patankar, Numerical Heat Transfer and Fluid Flow, McGraw-Hill, New York, NY, USA, 1980.

[22] W. Q. Tao, Numerical Heat Transfer, Xian Jiaotong University Press, Xian, China, 2nd edition, 2001.

[23] B. Z. Liu, Y. H. Su, and H. L. Zhang, MATLAB 7.0 from Entry to Master, Posts \& Telecom Press, Beijing, China, 2010.

[24] Y. Zhang, K. Du, J. P. He, L. Yang, and Y. J. Li, "Impact factors analysis of the enthalpy method and the effective heat capacity method on the transient nonlinear heat transfer in phase change materials (PCMs)," Numerical Heat Transfer Part A: Applications, vol. 65, no. 1, pp. 66-83, 2014.

[25] Y. Zhang, K. Du, M. A. Medina, and J. He, "An experimental method for validating transient heat transfermathematical models used for phase change materials(PCMs) calculations," Phase Transitions, vol. 87, no. 6, pp. 541-558, 2014. 

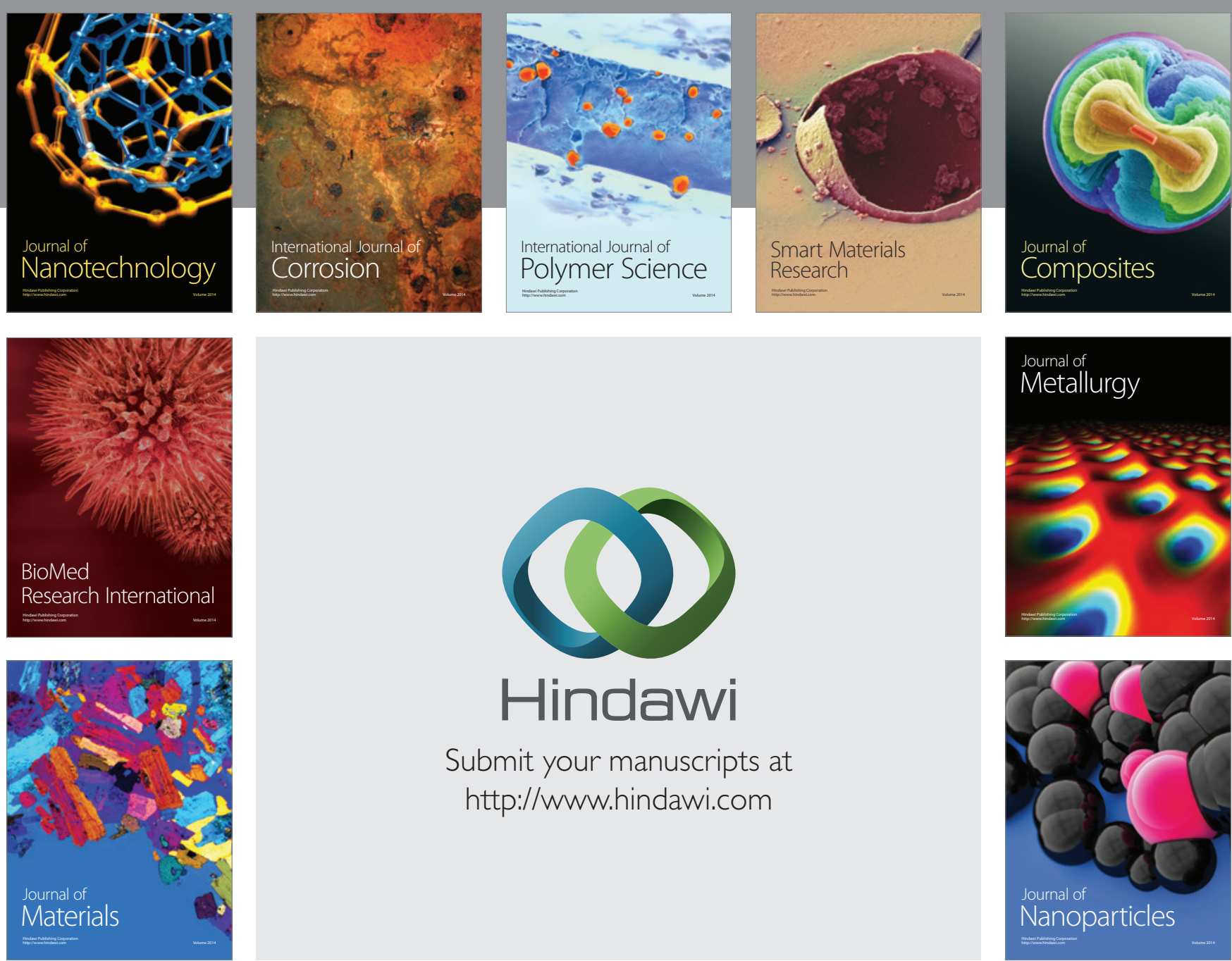

\section{Hindawi}

Submit your manuscripts at

http://www.hindawi.com

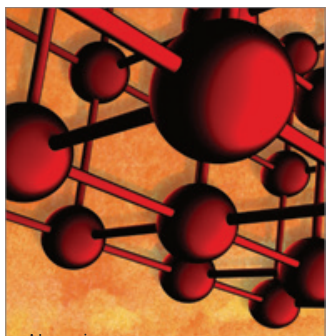

Materials Science and Engineering
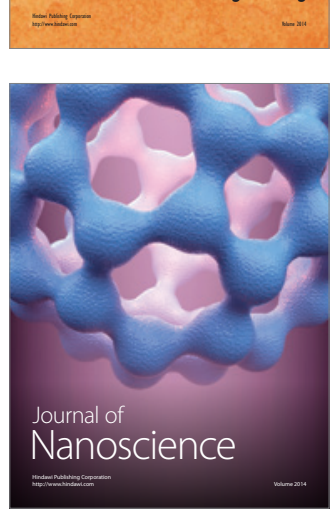
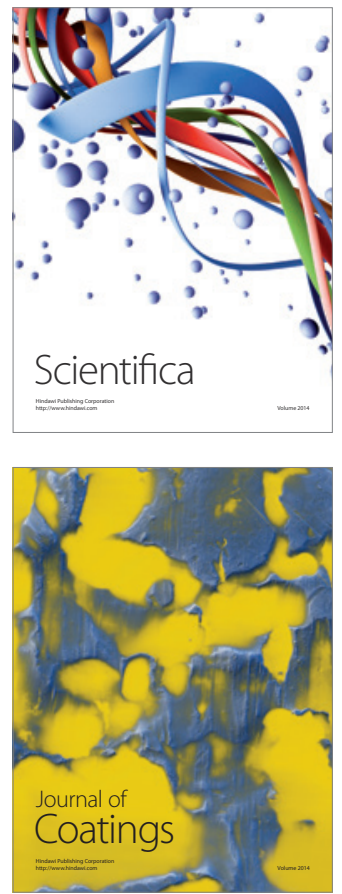
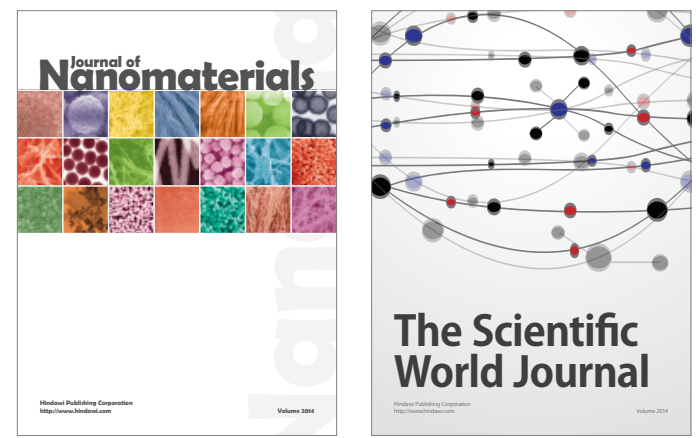

The Scientific World Journal
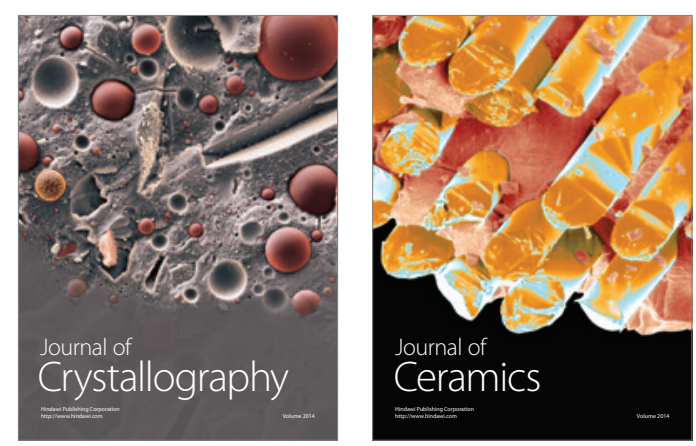
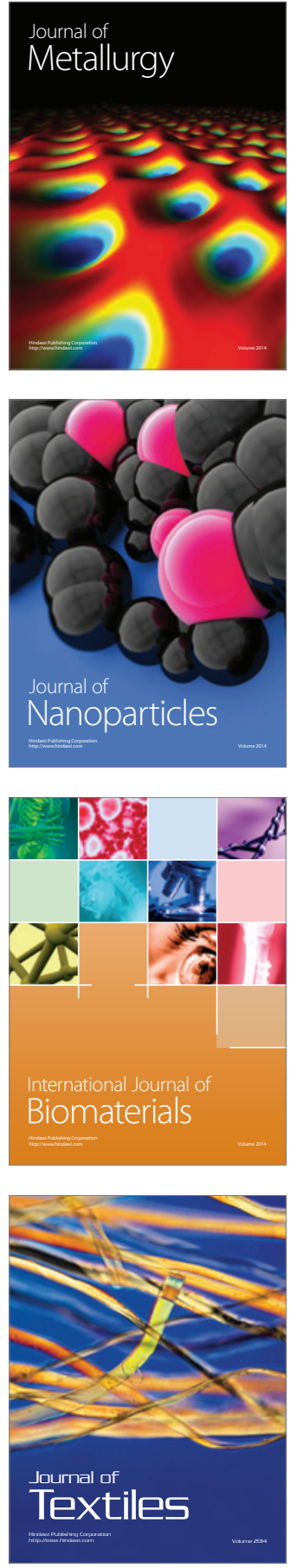